\title{
Integrated multistage supply chain inventory model of multiple retailers with imperfect production and inspection systems
}

Chi-Jie Lu

Fu Jen Catholic University

Ming Gu

Fu Jen Catholic University

Tian-Shyug Lee

Fu Jen Catholic University

Chih-Te Yang ( $\nabla$ ctyang@uch.edu.tw)

Chien Hsin University of Science and Technology https://orcid.org/0000-0001-7234-3107

\section{Research Article}

Keywords: inventory management, supply chain management, multiple retailers, imperfect production system, deterioration, inspection error

Posted Date: April 12th, 2021

DOI: https://doi.org/10.21203/rs.3.rs-201807/v1

License: (9) This work is licensed under a Creative Commons Attribution 4.0 International License. Read Full License 


\title{
Integrated multistage supply chain inventory model of multiple retailers with imperfect production and inspection systems
}

\author{
Chi-Jie Lu ${ }^{\mathrm{a}, \mathrm{b}}$, Ming Gu $\mathrm{a}^{\mathrm{a}}$, Tian-Shyug Lee ${ }^{\mathrm{a}, \mathrm{b}}$, and Chih-Te Yang ${ }^{\mathrm{c}, *}$ \\ a Graduate Institute of Business Administration, Fu Jen Catholic University, New Taipei \\ City 242, Taiwan \\ b Artificial Intelligence Development Center, Fu Jen Catholic University, New Taipei \\ City 242, Taiwan \\ c Department of International Business, Chien Hsin University of Science and \\ Technology, Taoyuan City 320, Taiwan \\ * Corresponding author. E-mail: ctyang@ uch.edu.tw Tel.: +886-2-2905-3986.
}

An integrated multistage supply chain inventory model containing a single manufacturer and multiple retailers is proposed to consider deteriorating materials and finished products with imperfect production and inspection systems. The main purpose is to jointly determine the manufacturer's production and delivery strategies and the retailers' replenishment strategies to maximize the integrated total profit. First, the individual total profit functions of the manufacturer and multiple retailers are established and are integrated to form the total profit function of the supply chain system. Then, to address the model complexity, an algorithm is proposed to obtain the optimal solution. Several practical numerical examples are presented to demonstrate the solution procedure, and a sensitivity analysis is performed on the major parameters. From the numerical results, several findings that differ from those in the previous literature were observed. First, retailers with larger market scale, better cost control, and inspection capabilities guarantee higher integrated total profit. Second, increasing the deterioration rates of materials and finished products affect the order quantity of materials in various ways. Third, the manufacturer's shipping strategy is rigid and not easily adjusted in the proposed model. The performance of the proposed model has several meaningful management implications.

Keywords: inventory management; supply chain management; multiple retailers; imperfect production system; deterioration; inspection error

\section{Introduction}

For supply chain systems, inventory management is a core activity of operation management. Efficient inventory management is essential to the healthy operation of the supply chain system. Inventory operations span the whole supply chain from manufacturer to retailer, including the processes of storing raw materials and finished products. The managers of a supply chain system must make a tradeoff between reactivity and cost. In other words, holding a large amount of inventory allows the overall supply chain to effectively respond to market changes; nevertheless, the demand for and storage of inventory generate a series of costs. Therefore, effectively integrating manufacturers and retailers in an appropriate production-inventory model 
and jointly determining the optimal production and ordering strategies are important issues for supply chain management to minimize the total inventory-related cost and maximize the total profit.

Traditional economic order quantity (EOQ) and economic production quantity (EPQ) models were both developed from the perspective of a single retailer or manufacturer. In recent years, inventory management studies have tended to consider the entire supply chain membership to establish an integrated production-inventory model. Integrated production-inventory models are an important direction of current inventory research (e.g., Darma Wangsa and Wee 2018; Venegas and Ventura 2018; Hayrutdinov, Ming, and Tong 2019). However, most of the previous models assumed that only a single manufacturer and single retailer are included in the productioninventory system. In fact, several large manufacturers deal with multiple retailers, and retailers of different scales and characteristics have competitive and coordinated relationships. For example, Nestlé cooperates with Walmart, Carrefour, Tesco, and other retailers. Therefore, considering the supply chain issues of multiple retailers can better reflect actual practice.

In inventory management, an important consideration is the deterioration of most types of products. Generally, deterioration is defined as the damage, spoilage, dryness, vaporization, or another process that reduces the usefulness of a product. Controlling and maintaining the inventories of deteriorating items are important issues for modern corporations (Wu, Ouyang, and Yang 2006). In the early literature, inventory models did not consider the deterioration of items, but researchers in the last decade have realized its importance for inventory control and incorporated it in models as a basic assumption (Dhandapani and Uthayakumar 2017; Soni and Suthar 2019). Regarding the deterioration of items in the supply chain inventory, previous studies only considered the deterioration of finished products (Tiwari et al. 2018; Maihami, Govindan, and Fattahi 2019). However, inventory in the supply chain system exists in different forms, such as materials or finished products. Therefore, the deterioration of raw materials should also be considered in supply chain inventory models.

In a competitive industrial environment, defective products may be produced because of factors such as incomplete production procedures, old equipment, or human negligence. In recent years, imperfect production systems and inventory management of defective products have been widely discussed (Ullah and Kang 2014; Kundu and Chakrabarti 2015; Barzegar and Sajadieh 2017; Mohanty, Kumar, and 
Goswami 2018). However, most studies that considered the inventory model of defective products have assumed no error in the inspection process; in other words, the inspection is $100 \%$ correct. In reality, the negligence of inspectors, old equipment, or outdated inspection techniques can lead to mistakes in the inspection results (Khan, Jaber, and Bonney 2011; Sarkar and Saren 2016). Thus, models that consider the issue of defective products should also consider the probability of inspection errors.

Based on the context described above, a model was developed in the present study for the production and inventory problem of deteriorating materials and finished products with imperfect production and inspection systems from the perspective of supply chain integration. A single manufacturer and multiple retailers were considered. The aim was to jointly determine the manufacturer's production and delivery strategies and the retailers' replenishment strategies to maximize the total profit of the entire supply chain system. First, the total profit functions were individually established for the manufacturer and retailers. The total profit functions were then integrated and solved mathematically. A unique algorithm was developed to obtain the optimal solution to address the model complexity. The model was applied to several realistic numerical examples to illustrate the solution procedure, and a sensitivity analysis was conducted on the main model parameters to obtain useful management implications for decision makers. The contributions of this study are as follows:

(1) Raw materials and finished products are included in the multistage supply chain inventory system.

(2) The supply chain system contains a single manufacturer and multiple retailers.

(3) The model considers imperfect production and inspection systems.

(4) A unique algorithm was developed to obtain the optimal solutions, and the properties of the optimal solutions were numerically proved.

(5) Optimal solutions for different competitive situations between retailers were considered and compared.

The rest of this paper is organized as follows. The related literature is briefly reviewed in Section 2. The notation and assumptions used throughout are listed in Section 3. The formula system and algorithm for obtaining the optimal solution are established in Section 4. In Section 5, numerical calculations are presented to explain the solution process, along with the sensitivity analysis of the main parameters. Finally, conclusions and suggestions are provided in Section 6. 


\section{Literature Review}

\subsection{Integrated supply chain inventory model}

Goyal (1976) first developed an integrated inventory model on the basis of the traditional EOQ model to determine the optimal joint inventory policy for a single vendor and a single buyer. Banerjee (1986) developed a joint economic lot size model, in which a vendor produces to order for a buyer on a lot-for-lot basis. Lu (1995) subsequently extended this model to a single vendor and multiple buyers for an integrated inventory model. Ha and Kim (1997) recognized that products should be delivered during production to comply with the spirit of just-in-time (JIT) manufacturing. Kelle, Al-khateeb, and Miller (2003) proposed the concept of multiple shipments for batch delivery. Since then, other researchers (e.g., Ho, Ouyang, and Su 2008; Lin 2009; Wu and Chen 2010; Lin and Ho 2011; Lou and Wang, 2013) have continued to explore strategies for integrated inventory models. Zhao, $\mathrm{Wu}$, and Yuan (2016) explored an integrated multistage supply chain with time-varying demand over a finite planning horizon. Wu and Zhao (2016) discussed supply chain models for two retailers and one supplier with a default risk under trade credit policy. Hariga, As'ad, Shamayleh (2017) proposed a multistage cold supply chain model with carbon tax regulation. Du and Lei (2018) discussed the competition and coordination of a supply chain with a single supplier and multiple retailers. Kogan (2019) studied the effect of wholesale prices with a quantity discount offered by a supplier to multiple retailers engaged in a Cournot-Nash competition. Although multi-retailer inventory models have been proposed, they usually consider only the inventory of finished products; the inventory of raw materials is not considered simultaneously.

\subsection{Inventory model of deteriorating items}

Ghare and Schrader (1963) first included deteriorating items in the EOQ model and assumed that the deterioration is subject to exponential decay. Fujiwara (1993) discussed deteriorating items and proposed an EOQ model related to freshness. $\mathrm{Wu}$, Ouyang, and Yang (2006) discussed an optimal replenishment policy for deteriorating items on the basis of stock-dependent demand and partial backlogging. Hsu, Wee, and Teng (2006) considered an optimal lot sizing model for deteriorating items with 
expiration dates. Lee and Dye (2012) proposed the preservation technology cost as a decision variable for deteriorated items. He and Huang (2013) discussed seasonally deteriorating products. Yang, Dye, and Ding (2015) proposed the optimal dynamic trade credit and preservation technology allocation for a deteriorating inventory model. Geetha and Udayakumar (2016) considered the residual value of deteriorating items. Tiwari et al. (2018) considered a two-echelon supply chain model for deteriorating items in which the demand rate is assumed as dependent on the stock level. Shah, Chaudhari, and Jani (2019) analyzed the inventory deterioration under dynamic prices. Khan et al. (2019b) proposed an inventory model for deteriorating items considering price-dependent demand. Shaikh et al. (2019) developed a two-warehouse deteriorating inventory model with advanced payment, partial backlogged shortages. Chakraborty et al. (2020) further explored a multi-item inventory model for noninstantaneous deteriorating items with multiple warehouses. Maihami, Govindan, and Fattahi (2019) discussed a three-echelon supply chain model of items with probabilistic deterioration rates. Agi and Soni (2020) proposed a deteriorating inventory model with age-, stock-, and price-dependent demand rates. However, the above studies only discussed the impact of the deterioration characteristics of finished products on the inventory and did not consider the deterioration of raw materials.

\subsection{Inventory model considering defective products}

Porteus (1986) found that defective products are related to the probability of processes going out of control and regarded product quality as a decision variable for production process issues. Salameh and Jaber (2000) extended the traditional EPQ/EOQ model by accounting for imperfect quality items. Huang (2004) discussed an integrated production-inventory model that considers process unreliability and defective items. Sana (2010) discussed imperfect quality items and rework. Khan, Jaber, and Bonney (2011) considered the possibility of errors during defective product inspection and established an EOQ model that accounts for imperfect items and inspection errors. Ouyang, Chang, and Shum (2012) discussed an EOQ model with defective items and partially permissible delay in payments. Vishkaei et al. (2014) discussed optimal lot sizing for screening processes with returnable defective items. Ullah and Kang (2014) discussed the effects of defects, inspection, and reworking on inventory. Chen, Lo, and Weng (2016) considered the effect of the product warranty period of imperfect production systems on the selling price. Taleizadeh, Khanbaglo, and Cárdenas-Barrón 
(2016) proposed an inventory model that considers imperfect products and partial backordering. Zhou, Chen, and Zhong (2016) considered trade credits, shortages, imperfect quality, and inspection errors to establish a synergic EOQ model. Barzegar and Sajadieh (2017) considered improving the quality of defective products in an integrated production-inventory model. Priyan and Manivannan (2017) discussed an inventory model that considers quality inspection errors and a fuzzy defective rate. Cheikhrouhou et al. (2018) established an inventory model that includes the quality inspection and return of defective items; to model the problem, they introduced misclassification errors (Types I and II). Khan, Ahmad, and Hussain (2019a) established an integrated supply chain model that includes inspection errors and purchase and repair options. Recently, Tiwari et al. (2020) developed a stochastic supply chain model where quality issues and inspection errors affect its coordination. These previous studies did not consider the inventory management of multiple retailers with different inspection capabilities. In the present study, an integrated supply chain inventory model was developed to consider the imperfect production system of a single manufacturer and different imperfect inspection systems of multiple retailers.

\subsection{Research gap analysis}

Table 1 reveals the main differences between the present study and previous studies in the relevant literature. Although previous studies have sufficiently considered the deterioration of finished products, they have generally focused on EPQ/EOQ models and given less attention to production-inventory models. To our knowledge, no study has considered the deterioration of raw materials and finished products simultaneously when developing a supply chain inventory model. Similarly, no study has considered both imperfect production and inspection systems in an integrated multistage supply chain system with multiple retailers. The present study fills the above research gaps and is the first to discuss an integrated multistage supply chain inventory model for multiple retailers with imperfect production and inspection systems.

Insert Table 1 here.

\section{Notation and Assumptions}


The notation and assumptions that were used to develop the multistage productioninventory model are described below.

\subsection{Notations}

$D_{i} \quad$ Market demand rate for retailer $i$, where $i=1,2, \ldots, k$

$P \quad$ Manufacturer's production rate

$A_{R_{i}} \quad$ Ordering cost of finished products per order for retailer $i$, where $i=$ $1, \ldots, k$

$A_{M} \quad$ Manufacturer's ordering cost of raw material per order

$r \quad$ Amount of raw materials required to produce one unit of the finished product

$S \quad$ Manufacturer's setup cost per production cycle

$s_{i} \quad$ Unit inspection cost for retailer $i$, where $i=1,2, \ldots, k$

$c_{m} \quad$ Manufacturer's unit raw material cost

$c_{v} \quad$ Manufacturer's unit production cost

$v \quad$ Manufacturer's unit selling price (retailers' unit purchase price)

$p \quad$ Retailers' unit selling price of the finished product

$h_{b_{i}} \quad$ Unit holding cost of finished products per unit time for retailer $i$, where $i=1,2, \ldots, k$

$h_{m} \quad$ Manufacturer's unit holding cost of raw material per unit time

$h_{v} \quad$ Manufacturer's unit holding cost of finished products per unit time

$w_{i} \quad$ Unit treatment cost (including penalty cost) of defective products returned by customers for retailer $i$, where $i=1,2, \ldots, k$

$u \quad$ Manufacturer's handling cost for defective products returned by retailers

$C_{T_{i}} \quad$ Fixed shipping cost per shipment for retailer $i$, where $i=1,2, \ldots, k$

$C_{t_{i}} \quad$ Variable shipping cost per unit for retailer $i$, where $i=1,2, \ldots, k$

$\alpha_{i} \quad$ Type I inspection error rate for retailer $i$, where $i=1,2, \ldots, k$ and $0<$ $\alpha_{i}<1$

$\beta_{i} \quad$ Type II inspection error rate for retailer $i$, where $i=1,2, \ldots, k$ and $0<$ $\beta_{i}<1$

$\theta_{m} \quad$ Deterioration rate of raw materials

$\theta_{v} \quad$ Deterioration rate of finished products

$\lambda \quad$ Defective rate of finished products, where $\lambda \in(0,1)$

$Q_{i} \quad$ Order quantity for retailer $i$, where $i=1,2, \ldots, k$ 
$n_{i} \quad$ Number of shipments from the manufacturer to retailer $i$ during a production cycle, where $i=1,2, \ldots, k$

$q_{i} \quad$ Quantity shipped from the manufacturer to retailer $i$ per shipment, where $i=1,2, \ldots, k$

$T_{v_{i}} \quad$ Length of the manufacturer's production cycle for retailer $i$, where $i=$ $1,2, \ldots, k$

$T_{s_{i}} \quad$ Length of the manufacturer's production period for retailer $i$, where $i=$ $1,2, \ldots, k$

$T_{p_{i}} \quad$ Length of time for the manufacturer to produce and deliver the first batch of finished products to retailer $i$, where $i=1,2, \ldots, k$

$T_{b_{i}} \quad$ Length of replenishment cycle for retailer $i$, where $i=1,2, \ldots, k$

The superscript represents the optimal value.

\subsection{Assumptions}

1. The multistage supply chain system comprises a single manufacturer, multiple retailers, a single material, and a single product.

2. The finished products produced by the manufacturer contain defective items, and they must be inspected by the retailers. Types I and II errors occur during the inspection process. Table 2 shows the inspection error ratio matrix for retailer $i$.

Insert Table 2 here.

3. The manufacturer's production rate (of non-defective products) is finite and greater than the sum of the retailers' demand rates; thus, it satisfies $\left[\left(1-\alpha_{i}\right)(1-\right.$ $\left.\lambda)+\beta_{i} \lambda\right] P>\sum_{i=1}^{k} D_{i}$. Otherwise, no inventory problems would occur.

4. Retailer $i$ orders $Q_{i}$ quantity of products each time and allows the manufacturer to divide the order into $n_{i}$ consignments. In each shipment, the manufacturer may $\operatorname{ship} q_{i}$ units to ensure that retailer $i$ receives $\left[\left(1-\alpha_{i}\right)(1-\lambda)+\beta_{i} \lambda\right] q_{i}$ units of non-defective products inspected.

5. After inspection, the retailers immediately return all defective products to the manufacturer; the defective products sold due to Type II inspection errors should also be returned by the customer.

6. Shortages are not allowed for either the manufacturer or retailers.

7. Types I and II error ratios of retailer $i$ are denoted by $\alpha_{i}$ and $\beta_{i}$, respectively. In practice, they can be estimated by using data from past inspection procedures. To 
facilitate the establishment of the model, $\alpha_{i}$ and $\beta_{i}$ were assumed to be known constants.

\section{Model Formulation and Solution}

In the present study, a multistage integrated supply chain production-inventory model that considers deteriorated items, defective items, and inspection errors has been established. The system is assumed to comprise a single manufacturer and multiple retailers. Each retailer $i$ has an order of $Q_{i}$ units; the manufacturer must deliver the order in $n_{i}$ batches, and each shipment quantity is $q_{i}$ (the freight cost is borne by retailers), where $i=1,2, \ldots, k$. When the manufacturer receives an order from retailer $i$, it also places an order with the raw material supplier and immediately purchases sufficient raw materials to supply a production cycle. Because the finished products contain defective products at a defective rate of $\lambda$ and the retailer will have inspection errors, the total shipment quantity, which is judged as non-defective by retailer $i$ for a production cycle (period length of $T_{v_{i}}$ ), is $\left[\left(1-\alpha_{i}\right)(1-\lambda)+\beta_{i} \lambda\right] Q_{i}$, and the quantity judged as non-defective for each shipment is $\left[\left(1-\alpha_{i}\right)(1-\lambda)+\beta_{i} \lambda\right] q_{i}$. To comply with the JIT inventory system, the manufacturer begins shipping during the production period and ships to retailer $i$ when the production quantity reaches $q_{i}$ units for the first time (period length of $T_{p_{i}}$ ). The manufacturer then ships $q_{i}$ units at regular intervals (period length of $T_{b_{i}}$ ). Furthermore, because the manufacturer's production rate is greater than the total demand rate, it may stop producing (period length is $T_{S_{i}}$ ) the product but continue to ship it regularly until the entire ordered quantity has been shipped. Figure 1 depicts the production, delivery, and inventory processes of the entire multistage supply chain system. Figure 2 presents the inventory levels of the manufacturer's material and products and the retailers' products for a complete production cycle.

\section{Insert Figures 1-2 here.}

The above notation and assumptions were used to establish the total profits per unit time of the retailers and manufacturer.

\subsection{Total profit per unit time for retailer $i$}

Since the finished products from the manufacturer contain defective items in each 
shipment, retailer $i$ immediately inspects the items upon receipt. Because inspection errors are possible, a ratio of $\left[\left(1-\alpha_{i}\right)(1-\lambda)+\beta_{i} \lambda\right]$ products per order will be judged as non-defective and sold, and a ratio of $\left[\alpha_{i}(1-\lambda)+\left(1-\beta_{i}\right) \lambda\right]$ products per order will be judged as defective and returned to the manufacturer immediately. Moreover, items will deteriorate during storage, so the inventory for retailer $i$ will be reduced by sales and deterioration, as shown in Figure 1. The dynamic change in the inventory level for retailer $i$ during the time period $\left[0, T_{b_{i}}\right]$ can be expressed by the following differential equation:

$$
\frac{d I_{R_{i}}(t)}{d t}+\theta_{v} I_{R_{i}}(t)=-D_{i}, \quad 0 \leq t \leq T_{b_{i}}, i=1,2, \ldots, k .
$$

Assuming the boundary condition $I_{R_{i}}\left(T_{b_{i}}\right)=0$, Equation (1) transforms into

$$
I_{R_{i}}(t)=\frac{D_{i}}{\theta_{v}}\left[e^{\theta_{v}\left(T_{b_{i}}-t\right)}-1\right], 0 \leq t \leq T_{b_{i}}, i=1,2, \ldots, k .
$$

Since the quantity judged as non-defective per order is $\left[\left(1-\alpha_{i}\right)(1-\lambda)+\beta_{i} \lambda\right] q_{i}$, Equation (2) can be used to obtain the quantity of non-defective items shipped from the manufacturer to retailer $i$ per shipment $q_{i}=I_{R_{i}}(0)$ as follows:

$$
\left[\left(1-\alpha_{i}\right)(1-\lambda)+\beta_{i} \lambda\right] q_{i}=I_{R_{i}}(0)=\frac{D_{i}}{\theta_{v}}\left(e^{\theta_{v} T_{b_{i}}}-1\right), i=1,2, \ldots, k .
$$

From Equation (3), the quantity $q_{i}$ is given by

$$
q_{i}=\frac{D_{i}}{\left[\left(1-\alpha_{i}\right)(1-\lambda)+\beta_{i} \lambda\right] \theta_{v}}\left(e^{\theta_{v} T_{b_{i}}}-1\right), i=1,2, \ldots, k .
$$

The total profit per unit time for retailer $i$ is determined by the sales revenue, ordering cost, inspection cost, purchasing cost, transportation cost, holding cost, and defective product handling cost. These are evaluated as follows:

1. Sales revenue:

The sales revenue per replenishment cycle for retailer $i$ is $p D_{i} T_{b_{i}}$. However, because of Type II errors during the inspection process, $\beta_{i} \lambda q_{i}$ defective products are returned by customers. Therefore, the sales revenue per unit time for retailer $i$ is $p D_{i}-\beta_{i} \lambda q_{i} / T_{b_{i}}$, where $i=1,2, \ldots, k$.

2. Ordering cost:

The ordering cost per replenishment cycle for retailer $i$ is $A_{R_{i}}$. Hence, the ordering cost per unit time for retailer $i$ is $A_{R_{i}} / T_{b_{i}}$, where $i=1,2, \ldots, k$.

3. Inspection cost:

The inspection cost per unit time for retailer $i$ is 
4. Purchasing cost:

$$
\frac{s_{i} q_{i}}{T_{b_{i}}}=\frac{s_{i} D_{i}\left(e^{\theta_{v} T_{b_{i}}}-1\right)}{\left[\left(1-\alpha_{i}\right)(1-\lambda)+\beta_{i} \lambda\right] \theta_{v} T_{b_{i}}}, i=1,2, \ldots, k .
$$

The manufacturer sends the quantity $q_{i}$ to retailer $i$ per replenishment, where $\left[\left(1-\alpha_{i}\right)(1-\lambda)+\beta_{i} \lambda\right] q_{i}$ gives the products judged as non-defective and the rest are judged as defective products and returned to the manufacturer immediately. Thus, the purchasing cost per unit time for retailer $i$ is $\frac{v\left[\left(1-\alpha_{i}\right)(1-\lambda)+\beta_{i} \lambda\right] q_{i}}{T_{b_{i}}}=$ $v D_{i}\left(e^{\theta_{v} T_{b_{i}}}-1\right) / \theta_{v} T_{b_{i}}, i=1,2, \ldots, k$.

5. Holding cost:

The inventory holding cost per unit time for retailer $i$ can be obtained as follows:

$$
\frac{h_{b_{i}}}{T_{b_{i}}} \int_{0}^{T_{b_{i}}} I_{R_{i}}(t) d t=\frac{h_{b_{i}} D_{i}}{\theta_{v}^{2} T_{b_{i}}}\left(e^{\theta_{v} T_{b_{i}}}-\theta_{v} T_{b_{i}}-1\right), i=1,2, \ldots, k .
$$

6. Transportation cost:

The transportation cost per replenishment cycle for retailer $i$ comprises the fixed $\operatorname{cost} C_{T_{i}}$ and variable cost $C_{t_{i}} q_{i}$ and is given by

$$
C_{T_{i}}+\frac{C_{t_{i}} D_{i}}{\left[\left(1-\alpha_{i}\right)(1-\lambda)+\beta_{i} \lambda\right] \theta_{v}}\left(e^{\theta_{v} T_{b_{i}}}-1\right)
$$

Hence, the transportation cost per unit time is

$$
\frac{1}{T_{b_{i}}}\left\{C_{T_{i}}+\frac{C_{t_{i}} D_{i}}{\left[\left(1-\alpha_{i}\right)(1-\lambda)+\beta_{i} \lambda\right] \theta_{v}}\left(e^{\theta_{v} T_{b_{i}}}-1\right)\right\}, i=1,2, \ldots, k .
$$

7. Defective product handling cost:

For retailer $i, \beta_{i} \lambda q_{i}$ units will be misjudged as non-defective during the inspection and sold and then will be returned by customers due to Type II errors. This results in handling costs for defective products, which includes penalty costs, freight costs, and loss of goodwill. If the handling cost for defective products per unit is $w_{i}$, the handling cost per unit time for retailer $i$ is $w_{i} \beta_{i} \lambda q_{i} / T_{b_{i}}, i=1,2, \ldots, k$.

Based on these details, the total profit per unit time for retailer $i$ can be obtained and is denoted as $T P_{i}\left(T_{b_{i}}\right)$ :

$$
\begin{aligned}
& T P_{i}\left(T_{b_{i}}\right)=\frac{\left(\theta_{v} p+h_{b_{i}}\right) D_{i}}{\theta_{v}}-\frac{1}{T_{b_{i}}}\left\{A_{R_{i}}+C_{T_{i}}+\frac{\left(p \beta_{i} \lambda+w_{i} \beta_{i} \lambda+s_{i}+C_{t_{i}}\right) D_{i}}{\left[\left(1-\alpha_{i}\right)(1+\lambda)+\beta_{i} \lambda\right] \theta_{v}}\left(e^{\theta_{v} T_{b_{i}}}-1\right)+\right. \\
& \left.\frac{\left.\theta_{v} v+h_{b_{i}}\right) D_{i}}{\theta_{v}^{2}}\left(e^{\theta_{v} T_{b_{i}}}-1\right)\right\}, i=1,2, \ldots, k .
\end{aligned}
$$

\subsection{Total profit for Manufacturer}

Within a production cycle, once the manufacturer receives an order from retailer $i$ for 
$Q_{i}$ units, it places an order with the raw material supplier and purchases enough raw materials for that production cycle. Because each unit of finished products requires $r$ units of raw materials, the manufacturer needs at least $r Q_{i}$ units of raw materials for one production cycle. Raw materials also deteriorate during storage. In the interval $\left[0, T_{S_{i}}\right]$, the raw material inventory level decreases because of production and deterioration, as shown in Figure 2. The dynamic changes in the manufacturer's raw material inventory level can be expressed by the following differential equation:

$$
\frac{d I_{M_{i}}(t)}{d t}+\theta_{m} I_{M_{i}}(t)=-r P, 0 \leq t \leq T_{s_{i}}, i=1,2, \ldots, k
$$

Under the boundary condition $I_{M_{i}}\left(T_{S_{i}}\right)=0$, the manufacturer's inventory level of materials per production cycle is given by

$$
I_{M_{i}}(t)=\frac{r P}{\theta_{m}}\left[e^{\theta_{m}\left(T_{s_{i}}-t\right)}-1\right], 0 \leq t \leq T_{s_{i}}, i=1,2, \ldots, k .
$$

To comply with the spirit of JIT manufacturing, as the manufacturer produces $q_{i}$ units of finished products, it delivers products to retailer $i$ immediately at the beginning of the production cycle. Then, a fixed shipment of $q_{i}$ units is repeated at intervals of $T_{b_{i}}$, and $n_{i}$ shipments take place in a production cycle, as shown in Figure 2. For each shipment, $\left[\alpha_{i}(1-\lambda)+\left(1-\beta_{i}\right) \lambda\right] q_{i}$ units of defective products are returned by the retailer and discarded. The manufacturer's inventory level of finished products changes because of production and deterioration during the interval $\left[0, T_{s_{i}}\right]$. Because the manufacturer's production rate for non-defective products is finite and greater than the demand rate, the manufacturer stops production once the inventory reaches a certain level $I_{\max }$, and the inventory level is only affected by the deterioration in the interval $\left[T_{s_{i}}, T_{v_{i}}\right]$. The manufacturer's inventory level of finished products at time $t$ during the interval $\left[0, T_{s_{i}}\right]$ can be expressed by the following differential equation:

$$
\frac{d I_{p_{i}}(t)}{d t}+\theta_{v} I_{p_{i}}(t)=P, 0 \leq t \leq T_{s_{i}}, i=1,2, \ldots, k .
$$

Under the boundary condition $I_{p_{i}}(0)=0$, the manufacturer's inventory level of finished products per production cycle is given by

$$
I_{p_{i}}(t)=\frac{P}{\theta_{v}}\left(1-e^{-\theta_{v} t}\right), 0 \leq t \leq T_{S_{i}}, i=1,2, \ldots, k .
$$

After the first $q_{i}$ units are completed at time $T_{p_{i}}$, the manufacturer immediately ships

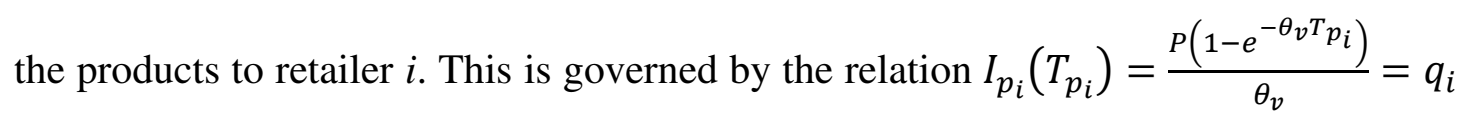


from Equation (3), which implies that

$$
T_{p_{i}}=\frac{1}{\theta_{v}} \ln \left[\frac{P}{P-\theta_{v} q_{i}}\right] .
$$

Hence, at $\left[T_{s_{i}}, T_{v_{i}}\right]$, because the manufacturer is no longer making products, the inventory changes are only due to item deterioration. At a certain time $t$, the inventory level of the finished products is governed by the following differential equation:

$$
\frac{d I_{d_{i}}(t)}{d t}+\theta_{v} I_{d_{i}}(t)=0, T_{s_{i}} \leq t \leq T_{v_{i}}, i=1,2, \ldots, k .
$$

Under the boundary condition $I_{d_{i}}\left(T_{v_{i}}\right)=n_{i} q_{i}$, Equation (11) can be solved to determine the inventory level during the interval $\left[T_{s_{i}}, T_{v_{i}}\right]$ :

$$
I_{d_{i}}(t)=n_{i} q_{i} e^{\theta_{v}\left(T_{v_{i}}-t\right)}, T_{s_{i}} \leq t \leq T_{v_{i}} .
$$

Equations (9) and (12) and the boundary condition $I_{p_{i}}\left(T_{s_{i}}\right)=I_{d_{i}}\left(T_{s_{i}}\right)$ can be used to obtain

$$
T_{s_{i}}=\frac{1}{\theta_{v}} \ln \left[\frac{P+n_{i} q_{i} \theta_{v} e^{\theta_{v} T_{v}}}{P}\right]
$$

For retailer $i$, the manufacturer's total profit includes the sales revenue, setup cost, material purchasing cost, production cost, material cost, holding cost, and defective product handling cost. These are evaluated as follows:

1. Sales revenue:

Because a ratio of $\left[\left(1-\alpha_{i}\right)(1-\lambda)+\beta_{i} \lambda\right]$ products in the quantity $Q_{i}$ delivered by the manufacturer to retailer $i$ per production cycle will be judged as nondefective, the manufacturer's total sales revenue for a production cycle is

$$
v\left[\left(1-\alpha_{i}\right)(1-\lambda)+\beta_{i} \lambda\right] Q_{i}=\frac{v n_{i} D_{i}}{\theta_{v}}\left(e^{\theta_{v} T b_{i}}-1\right) .
$$

Because the production cycle has a duration of $T_{v_{i}}$, the sales revenue per unit time is $\frac{v n_{i} D_{i}}{\theta_{v} T_{v_{i}}}\left(e^{\theta_{v} T_{b_{i}}}-1\right)$.

2. Setup cost:

The manufacturer's setup cost per unit time for the order from retailer $i$ is $\frac{S}{T_{v_{i}}}, i=$ $1,2, \ldots, k$.

3. Material purchasing cost:

The manufacturer's purchasing cost per unit time for the order from retailer $i$ is $\frac{A_{M}}{T_{v_{i}}}$, $i=1,2, \ldots, k$.

4. Production cost: 
For retailer $i$, the manufacturer's production cost order per unit time is $\frac{c_{v} P T_{s_{i}}}{T_{v_{i}}}, i=$ $1,2, \ldots, k$.

5. Material cost:

The manufacturer's raw material cost for retailer $i$ per production cycle is $c_{m} I_{M_{i}}(0)=\frac{c_{m} r P}{\theta_{m}}\left(e^{\theta_{m} T_{s_{i}}}-1\right)$, so the raw material cost for retailer $i$ per unit time is $\frac{c_{m} r P}{\theta_{m} T_{v_{i}}}\left(e^{\theta_{m} T_{s_{i}}}-1\right), i=1,2, \ldots, k$.

6. Holding cost:

The manufacturer's inventory holding cost for retailer $i$ comprises two parts: raw materials and finished products. The holding cost per unit time for raw materials is $\frac{h_{m}}{T_{v_{i}}} \int_{0}^{T_{s_{i}}} \quad I_{M_{i}}(t) d t=\frac{h_{m} r P}{\theta_{m}^{2}}\left(e^{\theta_{m} T_{s_{i}}}-\theta_{m} T_{s_{i}}-1\right)$.

For the holding cost of finished products, the manufacturer's cumulative inventory per production cycle can be obtained as follows:

$$
\int_{0}^{T_{S_{i}}} \quad I_{P_{i}}(t) d t+\int_{T_{s_{i}}}^{T_{v_{i}}} \quad I_{d_{i}}(t) d t-q_{i} T_{b_{i}}\left[1+2+\cdots+\left(n_{i}-1\right)\right] .
$$

Therefore, the holding cost of finished products per unit time is

$$
\begin{aligned}
\frac{h_{v}}{T_{v_{i}}}\left\{\int_{0}^{T_{s_{i}}} I_{P_{i}}(t) d t+\int_{T_{s_{i}}}^{T_{v_{i}}} I_{d_{i}}(t) d t-q_{i} T_{b_{i}}\left[1+2+\cdots+\left(n_{i}-1\right)\right]\right\} \\
=\frac{h_{v}}{T_{v_{i}}}\left\{\frac{P}{\theta_{v}^{2}}\left(e^{-\theta_{v} T_{s_{i}}}+\theta_{2} T_{s_{i}}-1\right)+\frac{n_{i} q_{i}}{\theta_{v}}\left[e^{\theta_{v}\left(T_{v_{i}}-T_{s_{i}}\right)}-1\right]\right. \\
\left.-\frac{n_{i}\left(n_{i}-1\right) D_{i} T_{b_{i}}}{2\left[\left(1-\alpha_{i}\right)(1-\lambda)+\beta_{i} \lambda\right] \theta_{v}}\left(e^{\theta_{v} T_{b_{i}}}-1\right)\right\}, \quad i=1,2, \ldots, k .
\end{aligned}
$$

The above can be used to obtain the inventory holding cost per unit time of the manufacturer:

$$
\begin{aligned}
& \frac{1}{T_{v_{i}}}\left\{\frac{h_{m} r P\left(e^{\left.\theta_{m} T_{S_{i}}-\theta_{m} T_{S_{i}}-1\right)}\right.}{\theta_{m}^{2}}+h_{v}\left\{\frac{P\left(e^{-\theta_{v} T_{s_{i}}}+\theta_{v} T_{S_{i}}-1\right)}{\theta_{v}^{2}}+\frac{n_{i} q_{i}\left[e^{\theta_{v}\left(T_{v_{i}}-T_{S_{i}}\right)}-1\right]}{\theta_{v}}-\right.\right. \\
& \left.\left.\frac{n_{i}\left(n_{i}-1\right) D_{i} T_{b_{i}}\left(e^{\theta_{v} T} b_{i-1}\right)}{2\left[\left(1-\alpha_{i}\right)(1-\lambda)+\beta_{i} \lambda\right] \theta_{v}}\right\}\right\}, i=1,2, \ldots, k .
\end{aligned}
$$

7. Defective product handling cost:

Because a quantity of $\left[\alpha_{i}(1-\lambda)+\left(1-\beta_{i}\right) \lambda\right] q_{i}$ products per shipment is judged as defective by retailer $i$ and returned directly, the manufacturer's handling cost per unit time for defective products from retailer $i$ is 


$$
\begin{gathered}
\frac{u}{T_{v_{i}}}\left[\alpha_{i}(1-\lambda)+\left(1-\beta_{i}\right) \lambda\right] n_{i} q_{i}=\frac{n_{i}\left[\alpha_{i}(1-\lambda)+\left(1-\beta_{i}\right) \lambda\right] n_{i}}{\left[\left(1-\alpha_{i}\right)(1-\lambda)+\beta_{i} \lambda\right] \theta_{v} T_{v_{i}}}\left(e^{\theta_{v} T_{b_{i}}}-1\right), \\
i=1,2, \ldots, k
\end{gathered}
$$

According to the above, for retailer $i$, the manufacturer's total profit per unit time is denoted by $T P_{v_{i}}\left(T_{v_{i}}, T_{s_{i}}, n_{i}\right)$ and is given by

$$
\begin{aligned}
T P_{v_{i}}\left(T_{v_{i}}, T_{s_{i}}, n_{i}\right) & \\
= & \frac{1}{T_{v_{i}}}\left\{\frac{v n_{i} D_{i}}{\theta_{v}}\left(e^{\theta_{v} T_{b_{i}}}-1\right)-\left(S+A_{M}\right)-\left(c_{v}-\frac{h_{m} r}{\theta_{m}}+\frac{h_{v}}{\theta_{v}}\right) P T_{s_{i}}\right. \\
& -\frac{\left(\theta_{m} c_{m}+h_{m}\right) r P\left(e^{\theta_{m} T_{s_{i}}}-1\right)}{\theta_{m}^{2}}+\frac{h_{v} n_{i}\left(n_{i}-1\right) D_{i} T_{b_{i}}\left(e^{\theta_{v} T_{b_{i}}}-1\right)}{2\left[\left(1-\alpha_{i}\right)(1-\lambda)+\beta_{i} \lambda\right] \theta_{v}} \\
& \left.-\left\{u\left[\alpha_{i}(1-\lambda)+\left(1-\beta_{i}\right) \lambda\right]-\frac{h_{v}}{\theta_{v}}\right\} n_{i} q_{i}\right\}, i=1,2, \ldots, k .
\end{aligned}
$$

$T_{v_{i}}=T_{p_{i}}+n_{i} T_{b_{i}}$; according to Equations (10) and (13), Equation (16) can be simplified to $T P_{v_{i}}\left(T_{b_{i}}, n_{i}\right)$. Based on the above, the total profit per unit time integrated for the multistage supply chain system is denoted by $\operatorname{JTP}\left(T_{b}, n\right)$ and is given by

$$
\begin{aligned}
& \operatorname{JTP}\left(T_{b}, n\right) \\
& =\sum_{i=1}^{k} \quad\left[T P_{i}\left(T_{b_{i}}\right)+T P_{i}\left(T_{b_{i}}, n_{i}\right)\right]=\sum_{i=1}^{k} \quad\left\{\frac{\left(\theta_{v} p+h_{b_{i}}\right) D_{i}}{\theta_{v}}-\frac{1}{T_{b_{i}}}\left\{A_{R_{i}}+C_{T_{i}}+\right.\right. \\
& \left.\frac{\left(p \beta_{i} \lambda+w_{i} \beta_{i} \lambda+s_{i}+C_{t_{i}}\right) D_{i}}{\left[\left(1-\alpha_{i}\right)(1+\lambda)+\beta_{i} \lambda\right] \theta_{v}}\left(e^{\theta_{v} T_{b_{i}}}-1\right)+\frac{\left(\theta_{v} v+h_{b_{i}}\right) D_{i}}{\theta_{v}^{2}}\left(e^{\theta_{v} T_{b_{i}}}-1\right)\right\}+\frac{1}{T_{v_{i}}\left(T_{b_{i}}\right)}\left\{\frac { v n _ { i } D _ { i } } { \theta _ { v } } \left(e^{\theta_{v} T_{b_{i}}}-\right.\right. \\
& \text { 1) }-\left(S+A_{M}\right)-\left(c_{v}-\frac{h_{m} r}{\theta_{m}}+\frac{h_{v}}{\theta_{v}}\right) P T_{S_{i}}\left(T_{b_{i}}\right)-\frac{\left(\theta_{m} c_{m}+h_{m}\right) r P}{\theta_{m}^{2}}\left[e^{\theta_{m} T_{s_{i}}\left(T_{b_{i}}\right)}-1\right]+ \\
& \left.\left.\frac{h_{v} n_{i}\left(n_{i}-1\right) D_{i} T_{b_{i}}}{2\left[\left(1-\alpha_{i}\right)(1-\lambda)+\beta_{i} \lambda\right] \theta_{v}}\left(e^{\theta_{v} T_{b_{i}}}-1\right)-\frac{n_{i} D_{i}\left\{\theta_{v} u\left[\alpha_{i}(1-\lambda)+\left(1-\beta_{i}\right) \lambda\right]-h_{v}\right\}}{\left[\left(1-\alpha_{i}\right)(1-\lambda)+\beta_{i} \lambda\right] \theta_{v}^{2}}\left(e^{\theta_{v} T_{b_{i}}}-1\right)\right\}\right\} \text {. }
\end{aligned}
$$

Because of the complexity of the model and integer value of $n_{i}$, finding closedform solutions for $T_{b}$ and $n$ is difficult, where $T_{b}=\left\{T_{b_{1}}, T_{b_{2}}, \ldots, T_{b_{k}}\right\}$, $n=\left\{n_{1}, n_{2}, \ldots, n_{k}\right\}$. The necessary conditions for maximizing $\operatorname{JTP}\left(T_{b}, n\right)$ for a given $n$ are obtained by solving the equation $\partial J T P\left(T_{b}, n\right) / \partial T_{b_{i}}=0 . J T P\left(T_{b}, n\right)$ is at its maximum when the Hessian matrix is negative definite. The matrix is defined as

$$
H=\left[\frac{\partial^{2} J T P\left(T_{b}, n\right)}{\partial T_{b_{1}}{ }^{2}} \cdots \frac{\partial^{2} J T P\left(T_{b}, n\right)}{\partial T_{b_{1}} \partial T_{b_{k}}} \vdots \because \vdots \frac{\partial^{2} J T P\left(T_{b}, n\right)}{\partial T_{b_{k}} \partial T_{b_{1}}} \cdots \frac{\partial^{2} J T P\left(T_{b}, n\right)}{\partial T_{b_{k}}{ }^{2}}\right] .
$$

Because of the high-power expression of the exponential function in Equation (17), the concavity property of the total profit per unit time cannot be proved through mathematical analysis. Alternatively, the concavity for a given $n_{i}$ can be verified 
through numerical analysis, as given in the following section. The following algorithm was developed to optimize $n_{i}$.

Algorithm

Step 1. Let $n_{1}=n_{2}=\cdots=n_{k}=1$.

Step 2. Find the value of $T_{b}$ (denoted by $\left.T_{b\left(n_{k}\right)}\right)$ by solving the equation $\partial J T P\left(T_{b}, n\right) /$ $\partial T_{b_{i}}=0$, where $i=1,2, \ldots, k$.

Step 3. Substitute $T_{b\left(n_{k}\right)}$ into (17) to obtain $\operatorname{JTP}\left(T_{b\left(n_{k}\right)}, n_{1}, n_{2}, \ldots, n_{k}\right)$ where $i=$ $1,2, \ldots, k$.

Step 4. Let $n_{k}=n_{k}+1$ and repeat Steps 2-3 to obtain JTP $\left(T_{b\left(n_{k}+1\right)}, n_{1}, n_{2}, \ldots, n_{k}+\right.$ $1)$, where $i=1,2, \ldots, k$.

Step 5. If $J T P\left(T_{b\left(n_{k}+1\right)}, n_{1}, n_{2}, \ldots, n_{k}+1\right)<J T P\left(T_{b\left(n_{k}+1\right)}, n_{1}, n_{2}, \ldots, n_{k}\right)$, then go to Step 6. Otherwise, go back to Step 4.

Step 6. Set $j=k-1$.

Step 7. If $j=1$, then $J T P\left(T_{b}^{*}, n^{*}\right)=J T P\left(T_{b\left(n_{1}\right)}, n_{1}, n_{2}, \ldots, n_{k}\right)$, and go to Step 8 .

Otherwise, repeat Steps $2-5$ to obtain $\operatorname{JTP}\left(T_{b\left(n_{j}\right)}, n_{1}, n_{2}, \ldots, n_{k}\right)$.

\section{Numerical Examples}

This section presents the results of applying the proposed model to reasonable data and a sensitivity analysis of major parameters.

Example 1. For convenience, the supply chain system was assumed to have one manufacturer and two retailers in this example. The parameters of Retailers 1 and 2 were as follows:

1) Demand parameter: $D_{1}=2000, D_{2}=1500$ (Retailer 1 has an advantage over Retailer 2);

2) Cost parameters: $A_{R_{1}}=\$ 100$ /order, $A_{R_{2}}=\$ 150 /$ order; $C_{T_{1}}=\$ 100 / \mathrm{ship}$, $C_{T_{2}}=\$ 150 / \mathrm{ship} ; C_{t_{1}}=\$ 0.6 /$ unit, $C_{t_{2}}=\$ 0.9$ /unit; $h_{b_{1}}=\$ 0.4 /$ unit/year, $h_{b_{2}}=\$ 0.6 /$ unit/year; $s_{1}=\$ 0.2 /$ unit, $s_{2}=\$ 0.3 /$ unit; $w_{1}=\$ 10 /$ unit, and $w_{2}=$ \$15/unit (Retailer 1 has an advantage over Retailer 2);

3) Inspection parameters: $\alpha_{1}=0.04, \alpha_{2}=0.06 ; \beta_{1}=0.08, \beta_{2}=0.12$ (Retailer 
1 has an advantage over Retailer 2).

The other parameters were set to the following values: $P=8000, A_{M}=\$ 300 /$ order, $S=\$ 500 /$ setup, $h_{m}=\$ 0.1 /$ unit/year, $h_{v}=\$ 0.3$ /unit/year, $u=\$ 3 /$ unit, $c_{m}=$ $\$ 0.5 /$ unit, $c_{v}=\$ 1$ /unit, $r=1, \theta_{m}=0.05, \theta_{v}=0.05, \lambda=0.05, p=\$ 50 /$ unit, and $v=\$ 20 /$ unit. The above realistic values were used to demonstrate the manufacturer's optimal production and shipping policies and the two retailers' ordering policies. The above algorithm was used to obtain the solution procedure of the proposed model, as given in Table 3. The results indicated that the manufacturer should prepare $n_{1}^{*}=13$ and $n_{2}^{*}=9$ shipments to Retailers 1 and 2, respectively, with corresponding shipping quantities of $q_{1}^{*}=442.164$ and $q_{2}^{*}=532.572$. The order quantities for Retailers 1 and 2 were $Q_{1}^{*}=5748.14$ and $Q_{2}^{*}=4793.15$, respectively. Finally, the optimal integrated total profit per unit time for the multistage supply chain system JTP* was $\$ 156,860.07$.

\section{Insert Table 3 here.}

Example 2. This example focused on retailers with different demand scale parameters $\left(D_{i}\right)$, cost control parameters $\left(A_{R_{i}}, h_{b_{i}}, C_{T_{i}}, C_{t_{i}}, s_{i}, w_{i}\right)$, and inspection capability parameters $\left(\alpha_{i}, \beta_{i}\right)$. The optimal decisions and total profits of the supply chain system were compared for various situations. For clarity, Table 4 describes the different situations considered in this example. Table 5 presents the optimal solutions for each situation.

\section{Insert Tables 4-5 here.}

The results in Table 5 led to the following insights:

1. Given the same cost and inspection parameters, a retailer with larger demand parameters has a larger optimal order quantity and total profit. The practical explanation is that a retailer with a larger market requires more inventory, which increases the total profit.

2. Given the same demand and inspection parameters, a retailer with lower cost parameters has a lower optimal order quantity but larger total profit. This indicates that a retailer who is more able to control costs can reduce the amount of inventory required and increase the total profit.

3. Given the same demand and inspection parameters, a retailer with a lower rate of inspection error has a lower optimal order quantity but a larger total profit. Thus, a retailer who is more capable of judging good/defective products can reduce the 
amount of inventory required, which increases the total profit. This result is similar to that of Khan, Ahmad, and Hussain (2019a), who found that improving the inspection capability has a positive impact on the profits of both buyers and sellers. The difference is that the present study further compared the optimal decisions and total profits of different retailers depending on their inspection capabilities.

4. Situations 1-4 and 8 indicate that increasing the demand parameters of the retailers reduces the values of the cost and inspection parameters; the number of shipments from the manufacturer increase, and the optimal profit of the manufacturer and optimal total profit of the supply chain system increase accordingly. For the management of the supply chain system, this indicates that the manufacturer's shipping strategy and total profit and integrated total profit are also affected by the market size of the retailer and the retailer's cost control and inspection capabilities. Increasing the market size, cost control, or inspection capability increases the number of shipments from the manufacturer, which increases the total profit of the manufacturer and integrated total profit.

5. Situations 1 and 5-8 indicate that changes to the demand parameters have the greatest impact on the retailers' order quantity and total profits, followed by the cost parameters. The inspection parameters have the smallest impact. Regarding the integrated total profit of the supply chain system, changes in cost parameters have the greatest impact, followed by demand parameters. Inspection parameters again have the smallest impact.

Example 3. In this example, a sensitivity analysis was performed on the major model parameters. For convenience, the data are the same as the values used in Example 1. Table 6 presents the numerical results for the effects of these parameters on the optimal solutions. The following observations can be made:

\section{Insert Table 6 here.}

1. Increasing the manufacturer's production rate or retailer's selling price reduced the retailers' order quantities of finished products and the manufacturer's order quantities of raw materials while increasing the integrated total profit. The increase in the integrated total profit of the supply chain with increased productivity and selling price is intuitive. However, it is interesting that productivity had a significant impact on the procurement of materials and ordering of finished products but no significant impact on the integrated profit, which is the 
opposite of the result for the selling price.

2. Increasing the manufacturer's ordering cost of raw materials, setup cost, or defective rate of finished products increased both the retailers' order quantities of finished products and the manufacturer's order quantities of raw materials while reducing the integrated total profit. Khan, Ahmad, and Hussain (2019a) found that the inspection rate directly affects the cost of disposing of defective products and the strategic relationship between the seller and buyer. Similarly, the present study found that increasing the defective rate of finished products increased the burden on the supply chain system, which caused the manufacturer and retailers to increase purchases to meet demand. The circulation and return of more defective products caused related wastes, which ultimately reduced the integrated total profit.

3. Increasing the manufacturer's holding cost of raw materials or finished products, raw material cost, production cost, selling price, handling cost for defective products, or deterioration rate of finished products reduced the retailers' order quantities of finished products and the manufacturer's order quantities of raw materials, which reduced the integrated total profit.

4. Increasing the amount of raw materials required to produce one unit of a finished product or the deterioration rate of raw materials increased the manufacturer's order quantities of raw materials and reduced the retailers' order quantities of finished products and the integrated total profit. Increasing the consumption of raw materials naturally increases the purchase volume of the manufacturer, and the increase in related costs reduces the integrated total profit of the supply chain system. Thus, if the loss rate or deterioration rate of raw materials can be effectively reduced, the integrated total profit will be increased.

5. The results in the previous literature (Fujiwara 1993; Hsu, Wee, and Teng 2006; Geetha and Udayakumar 2016) showed that increasing the deterioration rate of items reduced the order quantity of finished products to avoid losses due to the deterioration of excess orders. However, the present study considered the deteriorations of materials and finished products at the same time. Increasing the deterioration rates of materials and finished products had different effects on the order quantity of materials. Increasing the deterioration rate of materials increased the purchase quantity; however, increasing the deterioration rate of finished products decreased the purchase quantity. 
6. The manufacturer's shipping strategy was affected by changes to the manufacturer's production rate, ordering cost of raw materials, setup cost, holding cost of finished products, selling price, raw material cost, amount of raw materials required to produce one unit of a finished product, and the deterioration rate of finished products. The number of shipments increased with the manufacturer's ordering cost of raw material, setup cost, or selling price. For the retailer with inferior status, the manufacturer's shipping strategy was not easily changed, except for obvious changes to the manufacturer's production rate or selling price.

\section{Conclusions}

The present study explored the practicality of an integrated multistage supply chain inventory model with multiple retailers and imperfect production and inspection systems. The model expresses the imperfect production and inspection systems according to the ratio of defective products produced by the manufacturer and Types I and II error rates of the retailers' inspection system. Raw materials in the inventory stage and the deterioration of materials and products were also considered to improve the suitability of the model to actual situations. The present study aimed to clearly determine the manufacturer's production and delivery strategies and the retailers' replenishment strategies to maximize the total profit of the entire supply chain system. An algorithm was proposed to mathematically analyze the manufacturer's optimal production and shipping strategies and the retailers' optimal replenishment strategies. Numerical examples and a sensitivity analysis were conducted to obtain managerial insights:

1. The optimal decisions and total profits were compared for different retailer markets and cost control and demand inspection capabilities. Several insights were obtained: (1) Retailers with larger markets and better cost control and inspection capabilities guarantee a high integrated total profit for the supply chain system. (2) Changes in cost parameters have the greatest impact on the integrated total profit of the supply chain system, followed by demand parameters. Inspection parameters have the smallest impact.

2. The manufacturer's productivity has a significant impact on the procurement of raw materials and the ordering of finished products, but it has no significant 
impact on the integrated profit. The retailers' selling price has no significant impact on the procurement of raw materials and ordering of finished products, but it has a significant impact on the integrated profit.

3. If the deterioration rate of raw materials can be effectively reduced, the integrated total profit will be increased. However, this improvement requires investment; preservation technologies may be an interesting issue for future research.

4. In contrast to previous research, the proposed model considers the deterioration of materials and finished products at the same time. The results of the numerical examples showed that increasing the deterioration rates of materials and finished products have different effects on the order quantity of materials. Increasing the deterioration rate of materials increases the purchase quantity, whereas increasing the deterioration rate of finished products decreases the purchase quantity.

5. The manufacturer's shipping strategy is rigid. It is not easily adjusted except for changes to its production rate, ordering cost of raw materials, setup cost, holding cost of finished products, selling price, raw material cost, amount of raw materials required to produce one unit of a finished product, and deterioration rate of finished products.

The conclusions of this study should serve as a useful reference for decision makers in practical applications. Future research may focus on evaluating how different retailers can reduce the deterioration rate of finished products by investing in warehousing. The proposed model can also be extended by incorporating game theory, setting the manufacturer or one retailer as the leader and other retailers as followers, expanding demand rates as functions of time or inventory, or allowing shortages.

\section{Compliance with ethical standards}

Conflict of interest: All authors declare that that there is no conflict of interest regarding the publication of this article.

Ethical approval: This article does not contain any studies with human participants or animals performed by any of the authors.

\section{Authorship contributions:}

Chi-Jie Lu: Conceptualization, Project administration, Writing \& editing.

Ming Gu: Formal analysis, Software, Writing - original draft. 
Tian-Shyug Lee: Conceptualization, Supervision.

Chih-Te Yang: Methodology, Writing \& editing.

\section{References}

Agi, M. A., and H. N. Soni. 2020. "Joint pricing and inventory decisions for perishable products with age-, stock-, and price-dependent demand rate." Journal of the Operational Research Society 71(1): 85-99.

Banerjee, A. 1986. "A joint economic-lot-size model for purchaser and vendor." Decision Sciences 17(3): 292-311.

Barzegar Astanjin, M., and M. S. Sajadieh. 2017. "Integrated production-inventory model with price-dependent demand, imperfect quality, and investment in quality and inspection." AUT Journal of Modeling and Simulation 49(1): 43-56.

Chakraborty, D., Jana, D. K., \& Roy, T. K. 2020. "Multi-warehouse partial backlogging inventory system with inflation for non-instantaneous deteriorating multi-item under imprecise environment." Soft Computing, 24(19), 14471-14490.

Cheikhrouhou, N., B. Sarkar, B. Ganguly, A. I. Malik, R. Batista, and Y. H. Lee. 2018. "Optimization of sample size and order size in an inventory model with quality inspection and return of defective items." Annals of Operations Research 271(2): 445-467

Chen, C. K., C. C. Lo, and T. C. Weng. 2016. "Optimal production run length and warranty period for an imperfect production system under selling price dependent on warranty period." European Journal of Operational Research 259(2): 401-412.

Darma Wangsa, I., and H. M. Wee. 2018. "An integrated vendor-buyer inventory model with transportation cost and stochastic demand." International Journal of Systems Science: Operations \& Logistics 5(4): 295-309.

Dhandapani, J., and R. Uthayakumar. 2017. "Multi-item EOQ model for fresh fruits with preservation technology investment, time-varying holding cost, variable deterioration and shortages." Journal of Control and Decision 4(2): 70-80.

Du J., and Q. Lei. 2018. "Competition and coordination in single-supplier multipleretailer supply chain." Recent Developments in Data Science and Business Analytics, Springer, Cham: 45-53.

Fujiwara, O. 1993. "EOQ models for continuously deteriorating products using linear and exponential penalty costs." European Journal of Operational Research 70(1): 104-114.

Geetha, K. V., and R. Udayakumar. 2016. "Optimal lot sizing policy for noninstantaneous deteriorating items with price and advertisement dependent demand under partial backlogging." International Journal of Applied and Computational Mathematics 2(2): 171-193.

Ghare, P. M., and G. F. Schrader. 1963. "A model for exponentially decaying inventory." Journal of industrial Engineering 14(5): 238-243.

Goyal, S.K. 1976. "An integrated inventory model for a single supplier-single customer problem." International Journal of Production Research 15(1): 107111.

Ha, D., and S.L. Kim. 1997. "Implementation of JIT purchasing: an integrated approach.” Production Planning \& Control 8(2): 152-157.

Hariga, M., R. As'ad, and A. Shamayleh. 2017. "Integrated economic and environmental models for a multi stage cold supply chain under carbon tax 
regulation." Journal of Cleaner Production 166: 1357-1371.

Hayrutdinov, S., J. Ming, and L. Tong. 2019. "The effect of remanufacturing effort on closed-loop supply chain with stochastic demand." In 2019 5th International Conference on Transportation Information and Safety (ICTIS): 1213-1219, IEEE.

He, Y., and H. Huang. 2013. "Optimizing inventory and pricing policy for seasonal deteriorating products with preservation technology investment." Journal of Industrial Engineering: 793568, 7, 2013.

Ho, C.H., L.Y. Ouyang, and C.H. Su. 2008. "Optimal pricing, shipment and payment policy for an integrated supplier-buyer inventory model with two-part trade credit." European Journal of Operational Research 187(2): 496-510.

Hsu, P. H., H. M. Wee, and H. M. Teng. 2006. "Optimal lot sizing for deteriorating items with expiration date." Journal of Information and Optimization Sciences 27(2): 271-286.

Huang, C.K. 2004. "An optimal policy for a single-vendor single-buyer integrated production-inventory problem with process unreliability consideration." International Journal of Production Economics 91(1): 91-98.

Kelle, P., F. Al-khateeb, and P.A. Miller. 2003. "Partnership and negotiation support by joint optimal ordering/setup policies for JIT." International Journal of Production Economics 81-82: 431-441.

Khan, M., A. Ahmad, and M. Hussain. 2019a. "Integrated decision models for a vendor-buyer supply chain with inspection errors and purchase and repair options." The International Journal of Advanced Manufacturing Technology 104(9-12): 3221-3228.

Khan, M. A. A., A. A. Shaikh, G. C. Panda, I. Konstantaras, and A. A. Taleizadeh. 2019b. "Inventory system with expiration date: Pricing and replenishment decisions." Computers \& Industrial Engineering 132: 232-247.

Khan, M., M. Y. Jaber, and M. Bonney. 2011. "An economic order quantity (EOQ) for items with imperfect quality and inspection errors." International Journal of Production Economics 133: 113-118.

Kogan, K. 2019. "Discounting revisited: evolutionary perspectives on competition and coordination in a supply chain with multiple retailers." Central European Journal of Operations Research 27(1): 69-92.

Kundu, S., and T. Chakrabarti. 2015. "An integrated multi-stage supply chain inventory model with imperfect production process." International Journal of Industrial Engineering Computations 6(4): 568-580.

Lee, Y. P., and C. Y. Dye. 2012. "An inventory model for deteriorating items under stock-dependent demand and controllable deterioration rate." Computers \& Industrial Engineering 63(2): 474-482.

Lin, Y. J. 2009. "An integrated vendor-buyer inventory model with backorder price discount and effective investment to reduce ordering cost." Computers \& Industrial Engineering 56(4): 1597-1606.

Lin, Y. J., and C. H. Ho. 2011. "Integrated inventory model with quantity discount and price-sensitive demand." TOP 19(1): 177-188.

Lou K. R., and W. C. Wang. 2013. "A comprehensive extension of an integrated inventory model with ordering cost reduction and permissible delay in payments." Applied Mathematical Modelling 37(7): 4709-4716.

Lu, L. 1995. "A one-vendor multi-buyer integrated inventory model." European Journal of Operational Research 81(2): 312-323.

Maihami, R., K. Govindan, and M. Fattahi. 2019. "The inventory and pricing decisions in a three-echelon supply chain of deteriorating items under 
probabilistic environment." Transportation Research Part E: Logistics and Transportation Review 131: 118-138.

Mohanty, D. J., R. S. Kumar, and A. Goswami. 2018. "Vendor-buyer integrated production-inventory system for imperfect quality item under trade credit finance and variable setup cost." RAIRO-Operations Research 52(4): 1277-1293.

Ouyang, L., C. Chang, and P. Shum. 2012. "The EOQ with defective items and partially permissible delay in payments linked to order quantity derived algebraically." Central European Journal of Operations Research 20(1): 141-160.

Porteus, E. L. 1986. "Optimal lot sizing, process quality improvement and setup cost reduction." Operations research 34(1): 137-144.

Priyan, S., and P. Manivannan. 2017. "Optimal inventory modeling of supply chain system involving quality inspection errors and fuzzy defective rate." Opsearch 54(1): 21-43.

Salameh, M.K., and M.Y. Jaber. 2000. "Economic production quantity model for items with imperfect quality." International Journal of Production Economics 64(1-3): 59-64.

Sana, S. S. 2010. "A production-inventory model in an imperfect production process." European Journal of Operational Research 200(2): 451-464.

Sarkar, B., and S. Saren. 2016. "Product inspection policy for an imperfect production system with inspection errors and warranty cost." European Journal of Operational Research 248(1): 263-271.

Shah, N. H., U. Chaudhari, and M. Y. Jani. 2019. "Optimal control analysis for service, inventory and preservation technology investment." International Journal of Systems Science: Operations \& Logistics 6(2): 130-142.

Shaikh, A. A., Das, S. C., Bhunia, A. K., Panda, G. C., \& Khan, M. A. A. 2019. "A two-warehouse EOQ model with interval-valued inventory cost and advance payment for deteriorating item under particle swarm optimization." Soft Computing 23(24), 13531-13546.

Soni, H. N., and D. N. Suthar. 2019. "Pricing and inventory decisions for noninstantaneous deteriorating items with price and promotional effort stochastic demand." Journal of Control and Decision 6(3): 191-215.

Taleizadeh, A. A., M. P. S. Khanbaglo, and L. E. Cárdenas-Barrón. 2016. "An EOQ inventory model with partial backordering and reparation of imperfect products." International Journal of Production Economics 182: 418-434.

Tiwari, S., C. K. Jaggi, M. Gupta, and L. E. Cárdenas-Barrón. 2018. “Optimal pricing and lot-sizing policy for supply chain system with deteriorating items under limited storage capacity." International Journal of Production Economics 200: 278-290.

Tiwari, S., N. Kazemi, N. M. Modak, L. E. Cárdenas-Barrón, and S. Sarkar. 2020. "The effect of human errors on an integrated stochastic supply chain model with setup cost reduction and backorder price discount." International Journal of Production Economics 107643.

Ullah, M., and C. W. Kang. 2014. "Effect of rework, rejects and inspection on lot size with work-in-process inventory." International Journal of Production Research 52(7-8): 2448-2460.

Venegas, B. B., and J. A. Ventura. 2018. "A two-stage supply chain coordination mechanism considering price sensitive demand and quantity discounts." European Journal of Operational Research 264(2): 524-533.

Vishkaei, B. M., S. T. A. Niaki, M. Farhangi, and M. E. M. Rashti. 2014. "Optimal lot sizing in screening processes with returnable defective items." Journal of 
Industrial Engineering International 10(3): 70.

Wu, C., and Q. Zhao. 2016. "Two retailer-supplier supply chain models with default risk under trade credit policy." SpringerPlus 5(1): 1728.

Wu, K. S., L. Y. Ouyang, and C. T. Yang. 2006. "An optimal replenishment policy for non-instantaneous deteriorating items with stock-dependent demand and partial backlogging." International Journal of Production Economics 101(2): 369-384.

Wu, O. Q., and H. Chen. 2010. "Optimal control and equilibrium behavior of production-inventory systems.” Management Science 56(8): 1362-1379.

Yang, C. T., C. Y. Dye, and J. F. Ding. 2015. "Optimal dynamic trade credit and preservation technology allocation for a deteriorating inventory model." Computers \& Industrial Engineering 87: 356-369.

Zhao, S. T., K. Wu, and X. M. Yuan. 2016. "Optimal production-inventory policy for an integrated multi-stage supply chain with time-varying demand." European Journal of Operational Research 255(2): 364-379.

Zhou, Y.W., C.Y. Chen, and Y.G. Zhong. 2016. "A synergic economic order quantity model with trade credit, shortages, imperfect quality and inspection errors." Applied Mathematical Modelling 40(2): 1012-1028. 
Table 1. Major characteristics of previous relevant research and our proposed model.

\begin{tabular}{|c|c|c|c|c|c|c|}
\hline \multirow{2}{*}{ Reseraches } & \multirow{2}{*}{ Model } & \multirow{2}{*}{$\begin{array}{l}\text { Single/multiple } \\
\text { retailer(s) }\end{array}$} & \multicolumn{2}{|c|}{ Deterioration } & \multirow{2}{*}{$\begin{array}{l}\text { Imperfect } \\
\text { production } \\
\text { system } \\
\end{array}$} & \multirow{2}{*}{$\begin{array}{c}\text { Imperfect } \\
\text { inspection } \\
\text { system }\end{array}$} \\
\hline & & & $\begin{array}{l}\text { Finished } \\
\text { products }\end{array}$ & materials & & \\
\hline Wu and Chen (2010); Lin and Ho (2011); Lou and Wang (2013) & supply chain & single retailer & & & & \\
\hline Wu and Zhao (2016); Du and Lei (2018); Kogan (2019) & supply chain & multiple retailers & & & & \\
\hline $\begin{array}{l}\text { Zhao, Wu, and Yuan (2016); Hariga, As'ad, and Shamayleh } \\
\text { (2017) }\end{array}$ & $\begin{array}{l}\text { multistage } \\
\text { supply chain }\end{array}$ & single retailer & & & & \\
\hline $\begin{array}{l}\text { Geetha and Udayakumar (2016); Shah, Chaudhari, and Jani } \\
\text { (2019); Agi and Soni (2020) }\end{array}$ & EOQ model & single retailer & $\mathrm{V}$ & & & \\
\hline $\begin{array}{c}\text { Yang, Dye, and Ding (2015); Tiwari et al. (2018); Maihami, } \\
\text { Govindan, and Fattahi (2019) }\end{array}$ & supply chain & single retailer & $\mathrm{V}$ & & & \\
\hline $\begin{array}{l}\text { Vishkaei et al. (2014); Taleizadeh, Khanbaglo, and Cárdenas- } \\
\text { Barrón (2016) }\end{array}$ & EOQ model & single retailer & & & $\mathrm{V}$ & \\
\hline $\begin{array}{l}\text { Ullah and Kang (2014); Zhou, Chen, and Zhong (2016); } \\
\text { Cheikhrouhou et al. (2018) }\end{array}$ & EOQ model & single retailer & & & $\mathrm{V}$ & $\mathrm{V}$ \\
\hline Sana (2010); Barzegar and Sajadieh (2017) & supply chain & single retailer & & & $\mathrm{V}$ & \\
\hline $\begin{array}{l}\text { Priyan and Manivannan (2017); Khan, Ahmad, and Hussain } \\
\text { (2019a); Tiwari et al. (2020) }\end{array}$ & supply chain & single retailer & & & $\mathrm{V}$ & $\mathrm{V}$ \\
\hline The proposed paper & $\begin{array}{l}\text { multistage } \\
\text { supply chain }\end{array}$ & multiple retailers & $\mathrm{V}$ & $\mathrm{V}$ & V & V \\
\hline
\end{tabular}


Table 2. Inspection error matrix for retailer $i$.

\begin{tabular}{cccc}
\hline \multirow{2}{*}{ Truth } & \multicolumn{2}{c}{ Inspection results } & \multirow{2}{*}{ Total } \\
\cline { 2 - 3 } $\begin{array}{c}\text { Non- } \\
\text { defective }\end{array}$ & $\left(1-\alpha_{i}\right)(1-\lambda)$ & $\begin{array}{c}\alpha_{i}(1-\lambda) \\
(\text { Type-I error })\end{array}$ & $(1-\lambda)$ \\
\hline Defective & $\begin{array}{c}\beta_{i} \lambda \\
(\text { Type-II error })\end{array}$ & $\left(1-\beta_{i}\right) \lambda$ & $\lambda$ \\
\hline Total & {$\left[\left(1-\alpha_{i}\right)(1-\lambda)+\beta_{i} \lambda\right]$} & {$\left[\alpha_{i}(1-\lambda)+\left(1-\beta_{i}\right) \lambda\right]$} & 1 \\
\hline
\end{tabular}


Table 3. Solution procedure of Example 1 with the proposed algorithm.

\begin{tabular}{ccccccc}
\hline$n_{1}^{*}$ & $n_{2}^{*}$ & $q_{1}^{*}$ & $q_{2}^{*}$ & $Q_{1}^{*}$ & $Q_{2}^{*}$ & $J T P^{*}$ \\
\hline \multirow{3}{*}{12} & 8 & 461.496 & 563.776 & 5537.95 & 4510.21 & 156856.82 \\
& 9 & 461.496 & 532.572 & 5537.95 & 4793.15 & 156859.90 \\
& 10 & 461.496 & 505.968 & 5537.95 & 5059.68 & 156848.75 \\
\hline \multirow{3}{*}{13} & 8 & 442.164 & 563.776 & 5748.14 & 4510.21 & 156856.99 \\
& 9 & 442.164 & 532.572 & 5748.14 & 4793.15 & $156860.07 \leftarrow$ \\
& 10 & 442.164 & 505.968 & 5748.14 & 5059.68 & 156848.92 \\
\hline \multirow{3}{*}{14} & 8 & 424.992 & 563.776 & 5949.88 & 4510.21 & 156849.45 \\
& 9 & 424.992 & 532.572 & 5949.88 & 4793.15 & 156852.54 \\
& 10 & 424.992 & 505.968 & 5949.88 & 5059.68 & 156841.39 \\
\hline
\end{tabular}

Note: " $\longleftarrow$ " denotes the optimal solution generated by the proposed model. 
Table 4. Description of various situations with different parameters for the retailers.

\begin{tabular}{|c|c|c|c|c|}
\hline Situations & $\begin{array}{l}\text { Demand } \\
\text { scale }\end{array}$ & $\begin{array}{l}\text { Cost } \\
\text { control }\end{array}$ & $\begin{array}{l}\text { Inspection } \\
\text { capability }\end{array}$ & $\begin{array}{l}\text { Parameter set }\left\{D_{1}, D_{2}, A_{R_{1}}, A_{R_{2}}, h_{b_{1}}, h_{b_{2}} \text {, }\right. \\
\left.C_{T_{1}}, C_{T_{2}}, C_{t_{1}}, C_{t_{2}}, \alpha_{1}, \alpha_{2}, \beta_{1}, \beta_{2}, s_{1}, s_{2}, w_{1}, w_{2}\right\}\end{array}$ \\
\hline 1 & V & V & V & $\begin{array}{l}\{2000,1500,100,150,0.4,0.6,100,150,0.6,0.9, \\
0.04,0.06,0.08,0.12,0.2,0.3,10,15\}\end{array}$ \\
\hline 2 & $X$ & $\mathrm{~V}$ & $\mathrm{~V}$ & $\begin{array}{l}\{1750,1750,100,150,0.4,0.6,100,150,0.6,0.9, \\
0.04,0.06,0.08,0.12,0.2,0.3,10,15\}\end{array}$ \\
\hline 3 & V & $X$ & $\mathrm{~V}$ & $\begin{array}{l}\{2000,1500,125,125,0.5,0.5,125,125,0.75,0.75 \\
0.04,0.06,0.08,0.12,0.25,0.25,12.5,12.5\}\end{array}$ \\
\hline 4 & $\mathrm{~V}$ & $\mathrm{~V}$ & $X$ & $\begin{array}{l}\{2000,1500,100,150,0.4,0.6,100,150,0.6,0.9, \\
0.05,0.05,0.1,0.1,0.2,0.3,10,15\}\end{array}$ \\
\hline 5 & $\mathrm{~V}$ & $X$ & $X$ & $\begin{array}{l}\{2000,1500,125,125,0.5,0.5,125,125,0.75,0.75, \\
0.05,0.05,0.1,0.1,0.25,0.25,12.5,12.5\}\end{array}$ \\
\hline 6 & $X$ & V & $\mathrm{X}$ & $\begin{array}{l}\{1750,1750,100,150,0.4,0.6,100,150,0.6,0.9, \\
0.05,0.05,0.1,0.1,0.2,0.3,10,15\}\end{array}$ \\
\hline 7 & $X$ & $X$ & $\mathrm{~V}$ & $\begin{array}{l}\{1750,1750,125,125,0.5,0.5,125,125,0.75,0.75 \\
0.04,0.06,0.08,0.12,0.25,0.25,12.5,12.5\}\end{array}$ \\
\hline 8 & $X$ & $X$ & $X$ & $\begin{array}{l}\{1750,1750,125,125,0.5,0.5,125,125,0.75,0.75 \\
0.05,0.05,0.1,0.1,0.25,0.25,12.5,12.5\}\end{array}$ \\
\hline
\end{tabular}

Note: V indicates that Retailer 1 has an advantage over Retailer 2; X indicates that Retailers 1 and 2 perform the same. 
Table 5. Optimal solutions for various situations depending on the retailers' parameters.

\begin{tabular}{ccccccccccc}
\hline Situations & $n_{1}^{*}$ & $n_{2}^{*}$ & $q_{1}^{*}$ & $q_{2}^{*}$ & $Q_{1}^{*}$ & $Q_{2}^{*}$ & $T P B_{1}{ }^{*}$ & $T P B_{2}{ }^{*}$ & $T P V^{*}$ & $J T P^{*}$ \\
\hline 1 & 13 & 9 & 442.164 & 532.572 & 5748.14 & 4793.15 & 56442.2 & 40996.6 & 59421.4 & 156860 \\
\hline 2 & 11 & 10 & 451.056 & 547.219 & 4961.61 & 5472.19 & 49360.6 & 47915.9 & 59343.7 & 156620 \\
\hline 3 & 12 & 9 & 498.246 & 502.463 & 5978.95 & 4522.17 & 55811.8 & 41514.2 & 59369.4 & 156695 \\
\hline 4 & 13 & 9 & 444.327 & 529.994 & 5776.25 & 4769.95 & 56284.8 & 41132.3 & 59398.8 & 156816 \\
\hline 5 & 12 & 9 & 500.702 & 500.066 & 6008.43 & 4500.59 & 55644.3 & 41642.1 & 59345.7 & 156632 \\
\hline 6 & 11 & 10 & 453.212 & 544.527 & 4985.33 & 5445.27 & 49223.0 & 48074.2 & 59346.5 & 156644 \\
\hline 7 & 10 & 10 & 510.149 & 515.116 & 5101.49 & 5151.16 & 48803.8 & 48508.2 & 59309.0 & 156621 \\
\hline 8 & 10 & 10 & 512.613 & 512.613 & 5126.13 & 5126.13 & 48657.4 & 48657.4 & 59310.7 & 156625 \\
\hline
\end{tabular}


Table 6. Sensitivity analysis of other parameters for optimal solutions.

\begin{tabular}{|c|c|c|c|c|c|c|c|c|c|c|}
\hline Parameters & $\begin{array}{c}\text { Value } \\
\mathrm{s}\end{array}$ & $n_{1}^{*}$ & $n_{2}^{*}$ & $q_{1}^{*}$ & $q_{2}^{*}$ & $q_{m 1}^{*}$ & $q_{m 2}^{*}$ & $Q_{1}^{*}$ & $Q_{2}^{*}$ & $J T P^{*}$ \\
\hline \multirow{5}{*}{$P$} & 6,400 & 14 & 10 & 427.855 & 506.748 & $6,889.08$ & $5,915.19$ & $5,989.97$ & $5,067.48$ & 156,588 \\
\hline & 7,200 & 13 & 9 & 443.387 & 532.861 & $6,593.28$ & $5,551.20$ & $5,764.03$ & $4,795.75$ & 156,734 \\
\hline & 8,000 & 13 & 9 & 442.164 & 532.572 & $6,570.66$ & $5,545.69$ & $5,748.14$ & $4,793.15$ & 156,860 \\
\hline & 8,800 & 12 & 8 & 460.568 & 563.625 & $6,284.80$ & $5,172.08$ & $5,526.82$ & $4,509.00$ & 156,974 \\
\hline & 9,600 & 11 & 8 & 481.811 & 563.541 & $5,994.89$ & $5,169.82$ & $5,299.92$ & $4,508.92$ & 157,074 \\
\hline \multirow{5}{*}{$A_{M}$} & 240 & 12 & 9 & 457.243 & 528.061 & $6,235.29$ & $5,491.99$ & $5,486.92$ & $4,752.55$ & 156,904 \\
\hline & 270 & 13 & 9 & 440.253 & 530.321 & $6,538.48$ & $5,518.88$ & $5,723.28$ & $4,772.89$ & 156,882 \\
\hline & 300 & 13 & 9 & 442.164 & 532.572 & $6,570.66$ & $5,545.69$ & $5,748.14$ & $4,793.15$ & 156,860 \\
\hline & 330 & 13 & 9 & 444.068 & 534.812 & $6,602.72$ & $5,572.42$ & $5,772.88$ & $4,813.31$ & 156,839 \\
\hline & 360 & 13 & 9 & 445.963 & 537.043 & $6,634.68$ & $5,599.05$ & $5,797.51$ & $4,833.39$ & 156,817 \\
\hline \multirow{5}{*}{$S$} & 400 & 12 & 9 & 454.385 & 525.032 & $6,191.39$ & $5,456.00$ & $5,452.62$ & $4,725.29$ & 156,933 \\
\hline & 450 & 12 & 9 & 457.955 & 528.816 & $6,246.23$ & $5,500.96$ & $5,495.46$ & $4,759.34$ & 156,897 \\
\hline & 500 & 13 & 9 & 442.164 & 532.572 & $6,570.66$ & $5,545.69$ & $5,748.14$ & $4,793.15$ & 156,860 \\
\hline & 550 & 13 & 9 & 445.332 & 536.301 & $6,624.04$ & $5,590.18$ & $5,789.32$ & $4,826.71$ & 156,824 \\
\hline & 600 & 13 & 9 & 448.476 & 540.003 & $6,677.12$ & $5,634.44$ & $5,830.19$ & $4,860.03$ & 156,789 \\
\hline \multirow{5}{*}{$h_{m}$} & 0.08 & 13 & 9 & 446.407 & 536.224 & $6,642.18$ & $5,589.27$ & $5,803.29$ & $4,826.02$ & 156,893 \\
\hline & 0.09 & 13 & 9 & 444.266 & 534.386 & $6,606.07$ & $5,567.32$ & $5,775.46$ & $4,809.47$ & 156,876 \\
\hline & 0.1 & 13 & 9 & 442.164 & 532.572 & $6,570.66$ & $5,545.69$ & $5,748.14$ & $4,793.15$ & 156,860 \\
\hline & 0.11 & 13 & 9 & 440.1 & 530.782 & $6,535.91$ & $5,524.37$ & $5,721.30$ & $4,777.04$ & 156,844 \\
\hline & 0.12 & 13 & 9 & 438.072 & 529.015 & $6,501.82$ & $5,503.34$ & $5,694.93$ & $4,761.14$ & 156,828 \\
\hline \multirow{5}{*}{$h_{v}$} & 0.24 & 13 & 9 & 464.508 & 558.689 & $6,949.25$ & $5,859.07$ & $6,038.60$ & $5,028.20$ & 157,119 \\
\hline & 0.27 & 13 & 9 & 452.965 & 545.214 & $6,753.07$ & $5,696.87$ & $5,888.55$ & $4,906.92$ & 156,988 \\
\hline & 0.3 & 13 & 9 & 442.164 & 532.572 & $6,570.66$ & $5,545.69$ & $5,748.14$ & $4,793.15$ & 156,860 \\
\hline & 0.33 & 12 & 9 & 450.886 & 520.687 & $6,137.74$ & $5,404.45$ & $5,410.63$ & $4,686.18$ & 158,736 \\
\hline & 0.36 & 12 & 9 & 440.918 & 509.491 & $5,985.42$ & $5,272.17$ & $5,291.02$ & $4,585.42$ & 158,615 \\
\hline \multirow{5}{*}{$p$} & 40 & 13 & 9 & 442.24 & 532.747 & $6,571.93$ & $5,547.78$ & $5,749.12$ & $4,794.72$ & 122,049 \\
\hline & 45 & 13 & 9 & 442.202 & 532.659 & $6,571.29$ & $5,546.73$ & $5,748.63$ & $4,793.93$ & 139,454 \\
\hline & 50 & 13 & 9 & 442.164 & 532.572 & $6,570.66$ & $5,545.69$ & $5,748.14$ & $4,793.15$ & 156,860 \\
\hline & 55 & 13 & 9 & 442.127 & 532.484 & $6,570.02$ & $5,544.65$ & $5,747.65$ & $4,792.36$ & 174,266 \\
\hline & 60 & 13 & 9 & 442.089 & 532.397 & $6,569.39$ & $5,543.61$ & $5,747.16$ & $4,791.57$ & 191,671 \\
\hline \multirow{5}{*}{$v$} & 16 & 12 & 9 & 461.884 & 533.096 & $6,306.72$ & $5,551.94$ & $5,542.61$ & $4,797.86$ & 157,178 \\
\hline & 18 & 12 & 9 & 461.690 & 532.834 & $6,303.72$ & $5,548.81$ & $5,540.28$ & $4,795.50$ & 157,019 \\
\hline & 20 & 13 & 9 & 442.164 & 532.572 & $6,570.66$ & $5,545.69$ & $5,748.14$ & $4,793.15$ & 156,860 \\
\hline & 22 & 13 & 9 & 442.004 & 532.310 & $6,567.95$ & $5,542.58$ & $5,746.05$ & $4,790.79$ & 156,708 \\
\hline & 24 & 13 & 10 & 441.844 & 505.555 & $6,565.26$ & $5,894.46$ & $5,743.97$ & $5,055.55$ & 156,558 \\
\hline \multirow{5}{*}{$u$} & 2.4 & 13 & 9 & 442.255 & 532.740 & $6,572.18$ & $5,547.69$ & $5,749.32$ & $4,794.66$ & 157,068 \\
\hline & 2.7 & 13 & 9 & 442.210 & 532.656 & $6,571.42$ & $5,546.69$ & $5,748.73$ & $4,793.90$ & 156,964 \\
\hline & 3 & 13 & 9 & 442.164 & 532.572 & $6,570.66$ & $5,545.69$ & $5,748.14$ & $4,793.15$ & 156,860 \\
\hline & 3.3 & 13 & 9 & 422.119 & 532.488 & $6,569.90$ & $5,544.69$ & $5,747.55$ & $4,792.39$ & 156,756 \\
\hline & 3.6 & 13 & 9 & 442.074 & 532.404 & $6,569.13$ & $5,543.69$ & $5,746.96$ & $4,791.64$ & 156,652 \\
\hline \multirow{5}{*}{$c_{m}$} & 0.4 & 13 & 9 & 448.082 & 539.072 & $6,670.47$ & $5,623.30$ & $5,825.07$ & $4,851.65$ & 157,296 \\
\hline & 0.45 & 13 & 9 & 445.092 & 535.79 & $6,619.99$ & $5,584.08$ & $5,786.19$ & $4,822.11$ & 157,078 \\
\hline & 0.5 & 13 & 9 & 442.164 & 532.572 & $6,570.66$ & $5,545.69$ & $5,748.14$ & $4,793.15$ & 156,860 \\
\hline & 0.55 & 12 & 9 & 458.545 & 529.416 & $6,255.31$ & $5,508.10$ & $5,502.54$ & $4,764.74$ & 156,643 \\
\hline & 0.6 & 12 & 9 & 455.654 & 526.319 & $6,210.87$ & $5,471.28$ & $5,467.85$ & $4,736.87$ & 156,426 \\
\hline \multirow{5}{*}{$c_{v}$} & 0.8 & 13 & 9 & 451.994 & 543.884 & $6,736.62$ & $5,680.92$ & $5,875.92$ & $4,894.95$ & 157,717 \\
\hline & 0.9 & 13 & 9 & 446.996 & 538.134 & $6,652.12$ & $5,612.09$ & $5,810.95$ & $4,843.21$ & 157,288 \\
\hline & 1 & 13 & 9 & 442.164 & 532.572 & $6,570.66$ & $5,545.69$ & $5,748.14$ & $4,793.15$ & 156,860 \\
\hline & 1.1 & 12 & 9 & 456.669 & 527.186 & $6,226.47$ & $5,481.58$ & $5,480.03$ & $4,744.67$ & 156,434 \\
\hline & 1.2 & 12 & 9 & 451.995 & 521.967 & $6,154.73$ & $5,419.62$ & $5,423.94$ & $4,697.70$ & 156,008 \\
\hline \multirow{5}{*}{$r$} & 0.8 & 13 & 9 & 452.531 & 542.889 & $5,396.57$ & $4,535.19$ & $5,882.90$ & $4,886.00$ & 157,329 \\
\hline & 0.9 & 13 & 9 & 447.243 & 537.644 & $5,990.67$ & $5,045.60$ & $5,814.16$ & $4,838.79$ & 157,095 \\
\hline & 1 & 13 & 9 & 442.164 & 532.572 & $6,570.66$ & $5,545.69$ & $5,748.14$ & $4,793.15$ & 156,860 \\
\hline & 1.1 & 12 & 9 & 456.495 & 527.663 & $6,846.18$ & $6,035.98$ & $5,477.94$ & $4,748.97$ & 156,627 \\
\hline & 1.2 & 12 & 9 & 451.676 & 522.909 & $7,379.82$ & $6,516.95$ & $5,420.12$ & $4,706.18$ & 156,395 \\
\hline
\end{tabular}




\begin{tabular}{ccccccccccc}
\hline \multirow{6}{*}{$\theta_{m}$} & 0.04 & 13 & 9 & 443.34 & 533.57 & $6,563.75$ & $5,538.55$ & $5,763.42$ & $4,802.13$ & 156,869 \\
& 0.045 & 13 & 9 & 442.752 & 533.071 & $6,567.22$ & $5,542.13$ & $5,755.78$ & $4,797.64$ & 156,864 \\
& 0.05 & 13 & 9 & 442.164 & 532.572 & $6,570.66$ & $5,545.69$ & $5,748.14$ & $4,793.15$ & 156,860 \\
& 0.055 & 13 & 9 & 441.577 & 532.073 & $6,574.06$ & $5,549.24$ & $5,740.50$ & $4,788.65$ & 156,856 \\
& 0.06 & 13 & 9 & 440.99 & 531.573 & $6,577.42$ & $5,552.76$ & $5,732.87$ & $4,784.16$ & 156,851 \\
\hline \multirow{4}{*}{$\theta_{v}$} & 0.04 & 13 & 9 & 458.175 & 550.806 & $6,682.68$ & $5,613.30$ & $5,956.28$ & $4,957.25$ & 157,024 \\
& 0.45 & 13 & 9 & 450.04 & 541.582 & $6,626.86$ & $5,580.31$ & $5,850.52$ & $4,874.24$ & 156,942 \\
& 0.05 & 13 & 9 & 442.164 & 532.572 & $6,570.66$ & $5,545.69$ & $5,748.14$ & $4,793.15$ & 156,860 \\
& 0.055 & 12 & 9 & 453.640 & 523.792 & $6,246.37$ & $5,509.84$ & $5,443.68$ & $4,714.13$ & 156,780 \\
& 0.06 & 12 & 9 & 446.054 & 515.254 & $6,192.36$ & $5,473.11$ & $5,352.65$ & $4,637.29$ & 156,700 \\
\hline \multirow{6}{*}{$\lambda$} & 0.04 & 13 & 9 & 439.935 & 530.129 & $6,541.28$ & $5,523.68$ & $5,719.15$ & $4,771.16$ & 157,330 \\
& 0.045 & 13 & 9 & 441.045 & 531.346 & $6,555.91$ & $5,534.64$ & $5,733.59$ & $4,782.11$ & 157,096 \\
& 0.05 & 13 & 9 & 442.164 & 532.572 & $6,570.66$ & $5,545.69$ & $5,748.14$ & $4,793.15$ & 156,860 \\
& 0.055 & 13 & 9 & 443.293 & 533.807 & $6,585.53$ & $5,556.83$ & $5,762.81$ & $4,804.26$ & 156,622 \\
& 0.06 & 13 & 9 & 444.431 & 535.051 & $6,600.53$ & $5,568.05$ & $5,777.60$ & $4,815.46$ & 156,381 \\
\hline
\end{tabular}




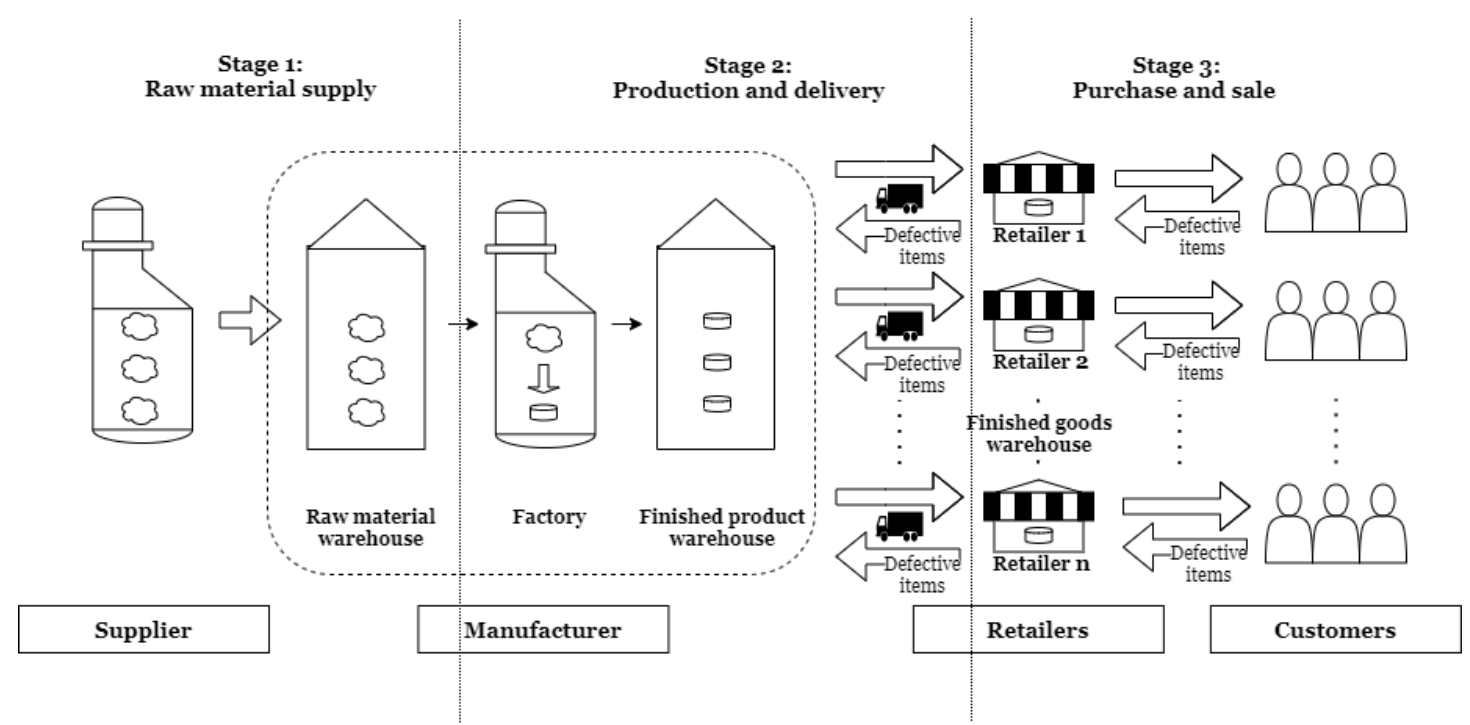

Figure 1. Multistage supply chain of a single manufacturer and multiple retailers considering defective products 
Inventory Level of finished products (Retailer $i$ )

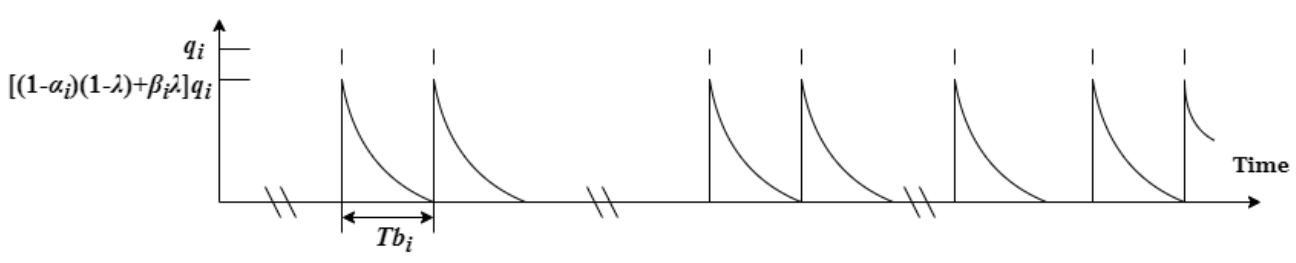

Inventory Level of finished products (Manufacturer)

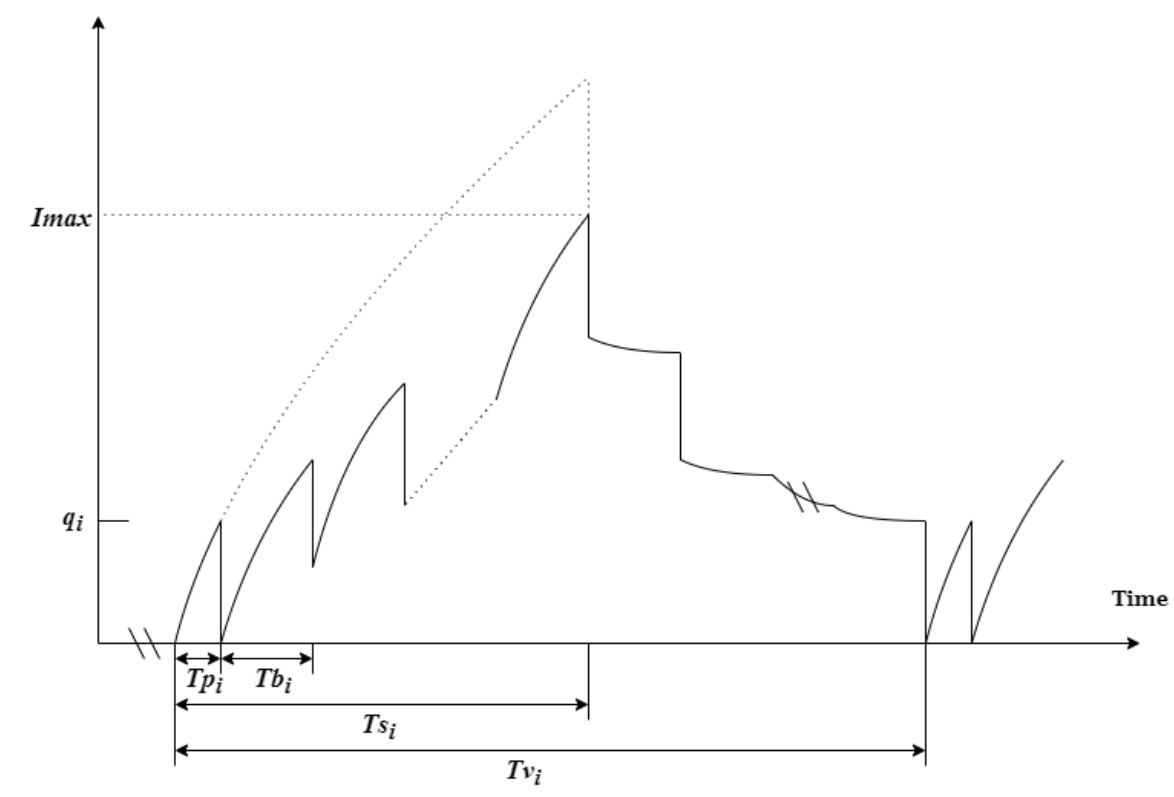

Inventory Level of raw materials (Manufacturer)

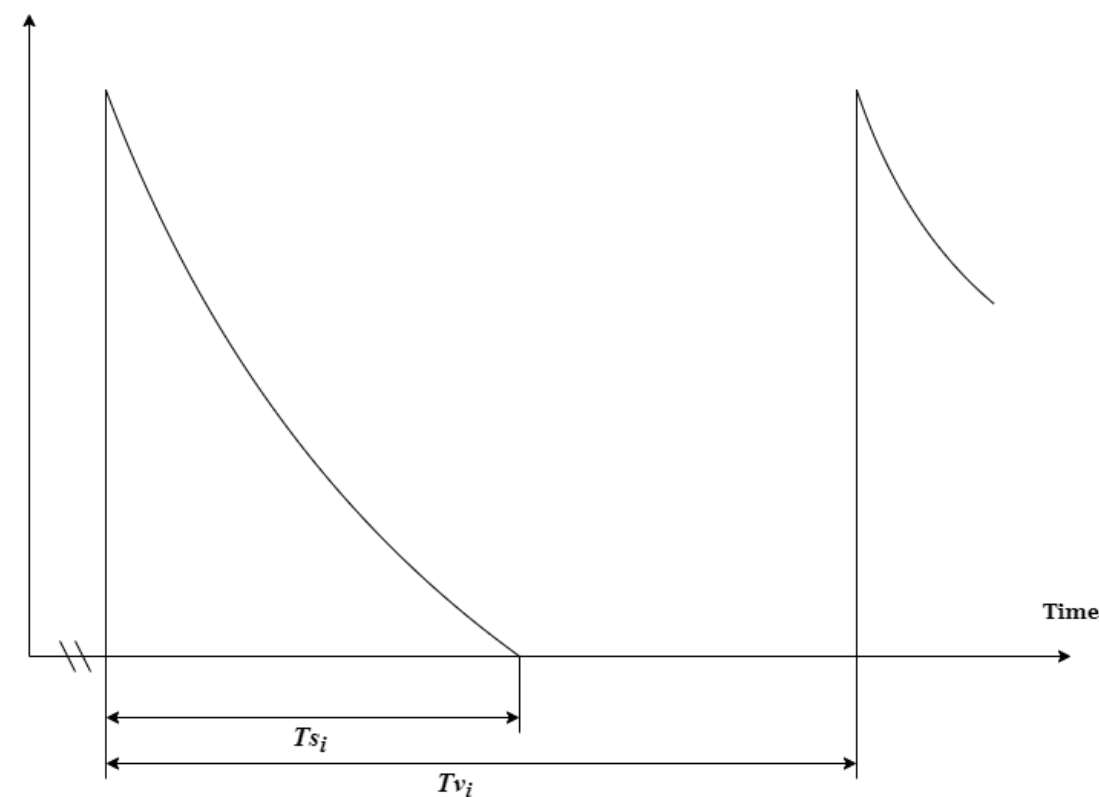

Figure 2. Inventory levels of materials and finished products in a production cycle 
Figures

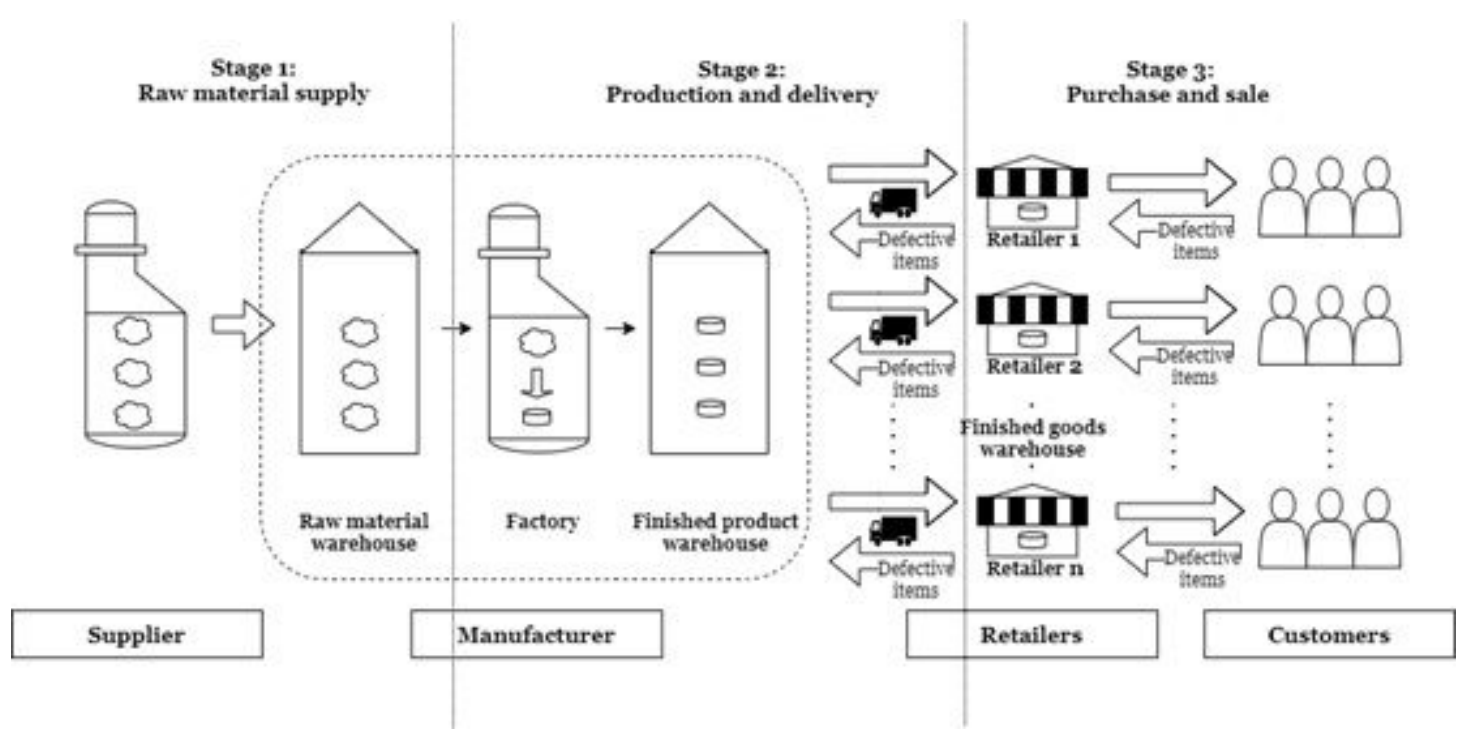

Figure 1

Multistage supply chain of a single manufacturer and multiple retailers considering defective products 
Inventory Level of finished products (Retaller i)

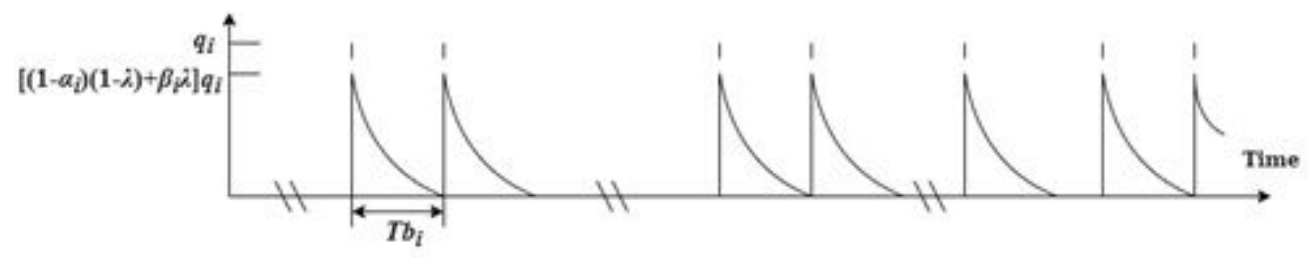

Inventory Level of finished products (Manufacturer)

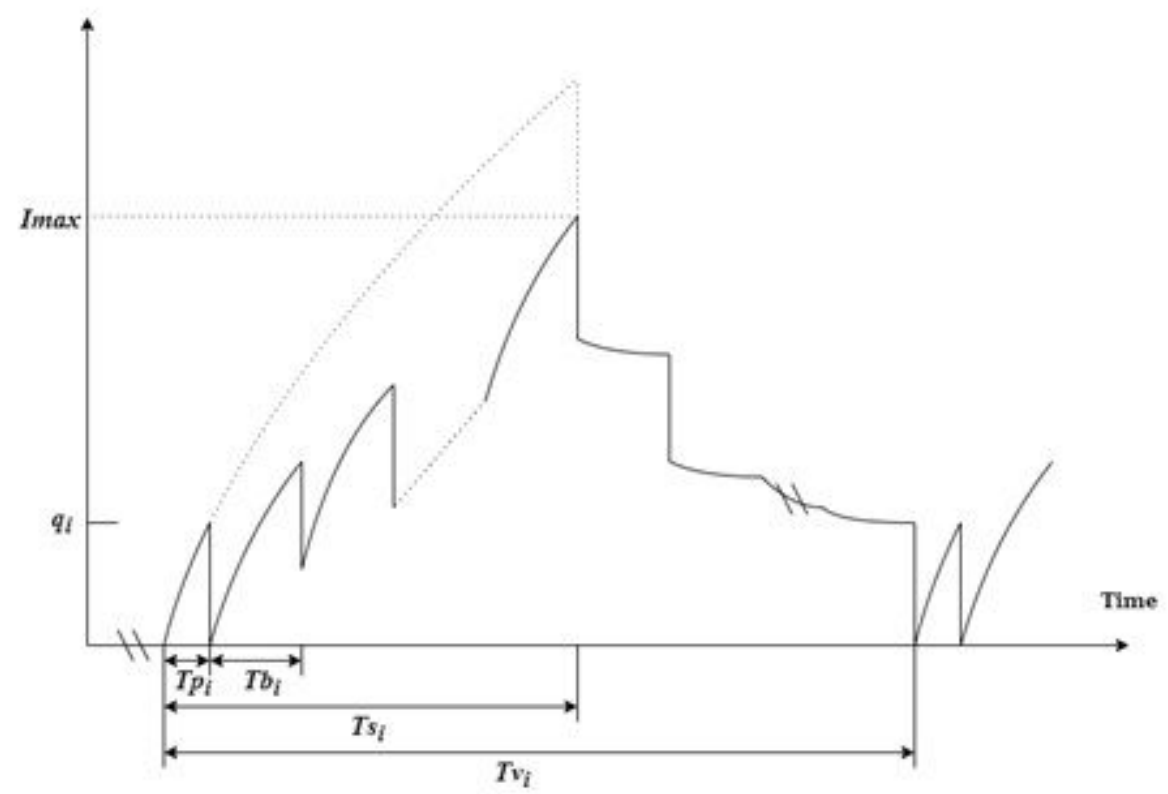

Inventory Level of raw materials (Manufacturer)

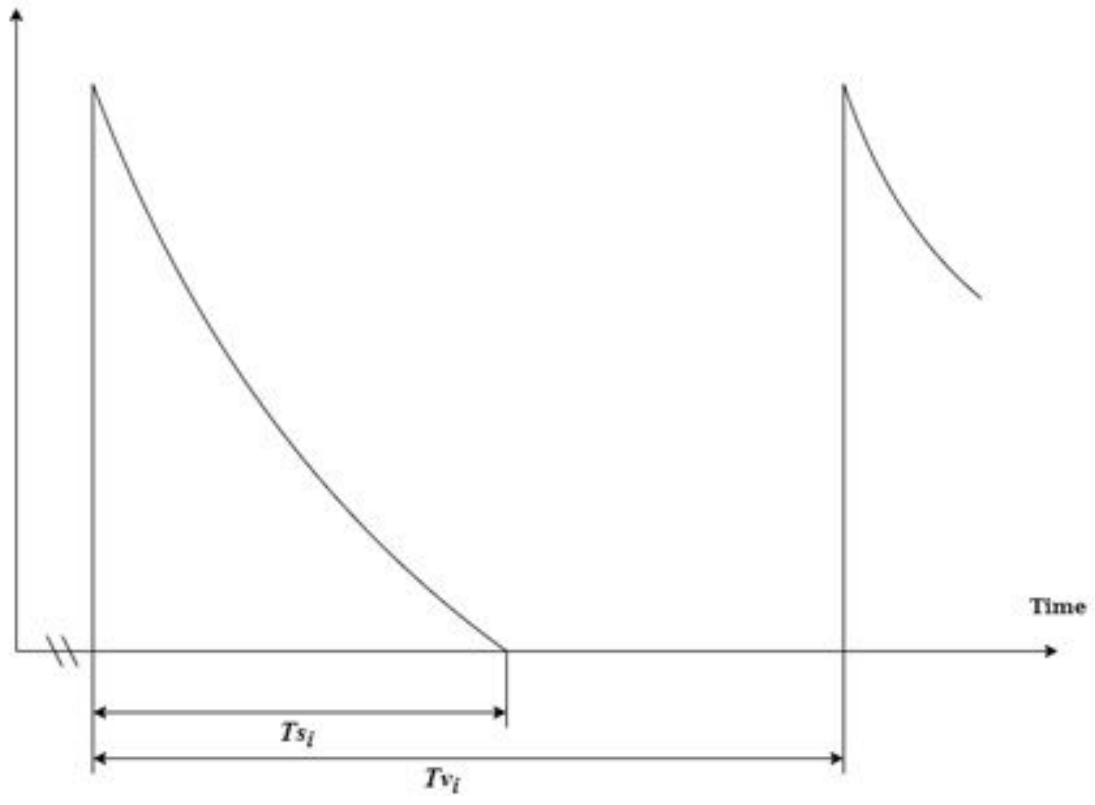

Figure 2

Inventory levels of materials and finished products in a production cycle 